\title{
Poblaciones guatemaltecas, hondureñas y salvadoreñas en México: perfiles propios y comparados con otras poblaciones latinoamericanas
}

\section{Guatemalan, Honduran and Salvadoran populations in Mexico: own and compared profiles with other Latin American populations}

\author{
Luis Felipe Jiménez-Chaves y Rodolfo Casillas-Ramírez \\ Facultad Latinoamericana de Ciencias Sociales, sede México
}

\section{Resumen}

En los últimos años el tema de la migración del norte centroamericano ha ganado presencia en México. La atención se ha centrado principalmente en la migración que transita por el país con el objetivo de llegar a Estados Unidos. En ese entorno, las poblaciones extranjeras inmigrantes aún no han sido materia de gran atención analítica, aunque hay apreciaciones sobre su volumen e incidencia pública. En este texto, con base en cuatro fuentes estadísticas, se caracteriza a nivel sociodemográfico y sociolaboral, el stock de inmigrantes de Guatemala, Honduras y El Salvador, de 1990 a 2015, en un ejercicio comparativo con el resto de las poblaciones latinoamericanas en México. El análisis permite concluir que hay comportamientos similares en indicadores asociados a la estructura familiar, sexo y participación económica, pero profundas diferencias en cuanto a estructura etaria, niveles de escolaridad, lugar de residencia y variables asociadas a la inserción laboral.

Palabras clave: Colectivos latinoamericanos, fuerza de trabajo inmigrante, indicadores sociodemográficos y sociolaborales.

\section{Abstract}

In recent years, the issue of Central American migration has gained a presence in Mexico. The focus has been mainly on the migration that transits the country with the aim of reaching the United States. In this environment, the foreign have been affected by a great analytical attention, although there are appreciations about their volume and public incidence. In this text, based in four statistic research, characterized the socio-demographic and socio-labor level, the stock of immigrants from Guatemala, Honduras and El Salvador, from 1990 to 2015, in a comparative exercise with the rest of the Latin American populations in Mexico. The analysis allow us to concluded that there are similar behaviors in indicators associated with family structure, gender and economic participation, but with differences in terms of age structure, levels of schooling, place of residence and variables associated with labor insertion.

Keywords: Latin American collectives, immigrant workforce, socio-demographic and socio-labor indicators. 


\section{INTRODUCCIÓN}

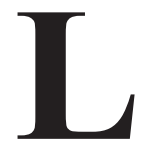

a migración internacional ha crecido de manera sostenida en el mundo. Para 2015, la Organización Internacional para las Migraciones (OIM, 2015) estimaba que se contaba con 240 millones de migrantes internacionales. Por su parte el Banco Mundial (2015) pronostica que en 2050 habrá 405 millones, lo que representa un incremento de 17 por ciento. Esos datos alarman a algunos sectores, más cuando observan a los flujos migratorios indocumentados. Esas preocupaciones son relativas cuando se pasa del dato agregado mundial al dato nacional.

México es escenario de diversas corrientes migratorias. La emigración de mexicanos hacia Estados Unidos es uno de los temas más abordados, al igual que las distintas relaciones que se establecen entre individuos desde el contexto de origen (México) y el receptor (Estados Unidos). ${ }^{1}$ De manera emergente, otro foco de análisis han sido los migrantes centroamericanos en tránsito por el país. ${ }^{2}$ La presencia de población extranjera en México, interés de esta investigación, es un ámbito menos explorado. Sin embargo, los inmigrantes internacionales a pesar de su baja presencia relativa, han presentado tasas de crecimiento dinámicas durante los últimos años y a su vez una gran heterogeneidad con respecto a la composición y estructura de las poblaciones que arriban cotidianamente.

En consecuencia, México no se caracteriza por ser un país típicamente receptor de extranjeros. Sin embargo, ha tenido un papel importante para inmigrantes que han salido de sus países en momentos coyunturales por razones políticas y económicas: españoles durante la guerra civil a finales de los años treinta; los inmigrantes conosureños en los años setenta por dictaduras militares en el sur continental; la población migrante del norte centroamericano (PMNC) que salió por conflictos armados y políticos a finales de los ochenta e inicios de los noventa; y de 2017 en adelante por un incremento de solicitantes venezolanos de refugio. Otros, con una pre-

\footnotetext{
1 Portes y Boröcz (1989) analizaron la idea de modos de incorporación en distintos contextos de llegada de los inmigrantes. Esta teoría de alcance intermedio fue aplicada empíricamente en los estudios de inmigración en la Ciudad de México realizados por Gandini (2015) y De la Peña (2015).

${ }^{2}$ E. Rodríguez, L. F. Ramos y J. C. Narváez han realizado distintos esfuerzos de recopilación y organización de datos para estimar los inmigrantes centroamericanos de transito irregular por México. El estudio más reciente estimó que en 2015 hubo 377 mil migrantes internacionales en tránsito (Rodríguez, 2016: 9). En años recientes este volumen puede haberse incrementado considerablemente debido a los flujos extraordinarios que se presentaron a finales de 2018 y 2019 y a los cuales se hará referencia en el texto.
} 
sencia relevante durante los distintos periodos han sido los colombianos y los cubanos. ${ }^{3}$

Esta inmigración latinoamericana, principalmente, ha estado mediada por importantes diferencias sociodemográficas y sociolaborales respecto a la región de procedencia y contexto de residencia. ${ }^{4}$ En el caso particular de los inmigrantes provenientes de Centroamérica en México, su presencia en el país se ha asociado de manera equívoca con los flujos de tránsito, pues se trata de dos flujos migratorios distintos, aunque no se niega la existencia de vasos comunicantes entre ellos. Históricamente, desde inicios del siglo XX existe un flujo laboral que ocurre en mayor volumen al Soconusco chiapaneco en temporada de cosecha agrícola, que con el tiempo y diversificación de mercados han incursionado en sectores informales del comercio y prestación de servicios. Aspectos como la vecindad geográfica, existencia de redes de apoyo, el menor costo de migrar y la jerarquía económica y social de México, han determinado una mayor presencia de nacionales de Guatemala y Honduras en localidades chiapanecas en mayor volumen, diversificación de actividades y tiempo, sin descartar presencia de otras nacionalidades. ${ }^{5}$

Por ejemplo, con datos del 2015, el informe de la CEPAL sobre el panorama de la migración internacional en México y Centroamérica muestra que la Producción Nacional de México "alcanzó en ese mismo año un volumen de 1,207 billones de dólares, sextuplicando el PIB de toda Centroamérica" (Canales y Rojas, 2017: 11). Sin embargo, con respecto a los niveles de pobreza, la situación de México se asemeja a El Salvador (41.2 y 41.6 por ciento respectivamente) y ambos países muy por debajo de Guatemala (67.7 por ciento) y Honduras (74.3 por ciento). Si bien los países relacionados comparten dinámicas sociales y migratorias semejantes, la situación socioeconómica de México se encuentra muy por encima de sus similares. En consecuencia, las poblaciones de interés para este texto son Guatemala, El Salvador y Honduras, por tres razones principales: i) por lo que en sí mismas han representado para la dinámica poblacional y migratoria en México; ii) por su peso relativo dentro del total de extranjeros residentes en el país; y iii) por sus posibles vinculaciones reales y po-

\footnotetext{
3 Algunos estudios en la inmigración hacia México son los de Palma (2006), Martínez Pérez y Aznar Molina (2017), Rodríguez (2010), Yankelevich (2011), Pardo y Dávila (2017) y Jiménez (2018).

${ }^{4}$ En uno de los capítulos del libro en preparación Caras conocidas y desconocidas de los procesos migratorios en México, de los autores, se caracteriza la población latinoamericana objeto de interés de este trabajo controlando por contexto rural y urbano en el periodo 1990-2015.

5 Ver, entre otros, Aguayo (1985); Dachary (1990); Grollova (1984); Helbig (1964); Mosquera (1990); Nájera Aguirre (2016); Ordóñez (1989); Zazueta y Pablos (1982).
} 
tenciales con los flujos centroamericanos en tránsito por tierras mexicanas, más a partir de los volúmenes extraordinarios que se presentaron a finales de 2018 e inicios de 2019.

A manera de ejemplo, entre los estudios sobre la inmigración centroamericana en México destacan los de Castillo y Vázquez (2010), Peña (2015), Masferrer y Pederzini (2017). En el caso del primer documento se resalta que la inmigración de guatemaltecos a México se ha consolidado por factores sociohistóricos como la situación de colindancia entre ambos países, la permanencia de redes de apoyo para individuos y grupos familiares, y la consolidación de los mercados transfronterizos de fuerza de trabajo en la frontera sur. Peña (2015) en su investigación sobre los salvadoreños en Ciudad de México, resalta que las personas que arriban a México desde este país lo hacen de la mano de las redes migratorias (salvadoreños que permanecieron en México después de los exilios de los años ochenta) que les ayudan a incorporarse laboralmente o buscar refugio; o bien otro cúmulo de salvadoreños que en su intento de llegar a Estados Unidos declinan debido a las amplias dificultades existentes. Masferrer y Pederzini (2017) ofrecen un panorama general de la inmigración centroamericana en México en lo que va del siglo XXI, diferenciando entre población con arribo reciente y antiguo. Resaltan que existen diferencias importantes en las tres nacionalidades de interés de su investigación, asociado a la dinámica demográfica de cada uno de los países. No obstante, esta inmigración se caracteriza por concentrarse en edades laborales, bajos niveles de escolaridad y acentuarse en los municipios del sur del país, especialmente en Chiapas.

En virtud del lugar de origen, en este estudio analizamos la inmigración latinoamericana en México en los últimos 25 años, con base a los últimos Censos de Población y Vivienda y la Encuesta Intercensal 2015, con particular hincapié en las tres nacionalidades de interés ya dichas. La idea es caracterizarlas con indicadores sociodemográficos y sociolaborales y delinear un análisis comparativo con la inmigración latinoamericana en general. Nos interesa responder a estas interrogantes: ¿cuáles son las principales diferencias en la estructura y composición de los inmigrantes intrarregionales en el país?; y ¿cómo han evolucionado dichas características en los últimos años? La pertinencia de responder es mayor debido a los flujos de mayor volumen llegados a México a finales de 2018 y primeros meses de 2019 y que, por distintas razones, tendrán que permanecer en México en espera de respuesta a su solicitud de refugio por parte de Estados Unidos. La mayoría de esa población es oriunda de los tres países mencionados y, 
en principio, dado que aún no hay información estadística disponible sobre su perfil sociolaboral, se puede hipotetizar que tiene gran similitud con la de los flujos que les ha antecedido. ${ }^{6}$

Las notas periodísticas y expresiones comunes sobre la "excesiva inmigración centroamericana permanente en México ${ }^{7 "}$ " carecen de solvencia y proporcionalidad, dado que, si bien la mayoría transita por México u ocurre como trabajadores temporales fronterizos, ${ }^{8}$ son pocos los que deciden permanecer o residir en el país, al menos hasta finales de 2018. Además, se espera que existan rasgos diferenciales importantes al interior de los distintos colectivos de inmigrantes intrarregionales que se relacionan con las distintas causas y nacionalidades de origen de la inmigración hacia México.

Este artículo se subdivide en cinco apartados: el primero comprende la presente introducción que contextualiza la inmigración centroamericana en México y cita algunos de los trabajos relacionados con el tema; en un segundo momento se describen los principales aspectos metodológicos de la investigación y las bondades y limitaciones de las fuentes de información utilizadas; en los subsiguientes segmentos figuran los resultados de investigación divididos en aspectos sociodemográficos y sociolaborales. En la última parte del documento se realizan algunas reflexiones finales que, insistimos, son importantes tener en cuenta ante el "estacionamiento" de cifras crecientes de solicitantes de refugio en Estados Unidos que esperarán en México por tiempo indefinido la respuesta a su solicitud presentada durante los primeros meses de 2019.

\section{Metodología Y FUENTES dE INFORMACIÓN}

Esta investigación describe y compara las poblaciones seleccionadas en función de diversos grupos de interés y distintos periodos de observación. La población considerada como inmigrante fue toda aquella que en el momento del levantamiento del Censo o en la Encuesta develó nacer en un

\footnotetext{
${ }^{6}$ Dado que lo ocurrido de octubre de 2018 a agosto de 2019 está captado por la prensa y medios electrónicos casi todos los días, en este texto no se hace referencia a las fuentes hemerográficas consultadas diariamente, sino que se registra el nombre de tres fuentes consultadas durante el tiempo mencionado: La Jornada, Milenio, Reforma.

7 Por citar algunos artículos periodísticos, se pueden revisar los de González (2014) y Nájar (2013).

8 Este tipo de Visa refiere a la de Visitante Trabajador Fronterizo, que por términos del artículo 52, Fracción III de la Ley de Migración y de los artículos 132 y 136 de su Reglamento, permite la internación temporal de colectivos de migrantes centroamericanos. En su mayoría guatemalte$\cos$.
} 
país diferente a México, ${ }^{9}$ las fuentes consideran a los residentes habituales, es decir, individuos que residen en un "lugar de alojamiento específico para dormir, comer, preparar sus alimentos, protegerse del medio y al que puede volver en el momento que lo desee" (INEGI, 2015: 32)

En cuanto a las variables analizadas se utilizaron todas las que permitieran la comparabilidad entre las distintas fuentes de información, a nivel sociodemográfico: el sexo, edad, niveles de escolaridad, etnia, asistencia escolar, tipo de hogar, situación conyugal, ubicación territorial; y en la escala sociolaboral la condición de actividad, sector económico y categoría ocupacional de inserción en el mercado de trabajo.

En el total de indicadores elaborados se emplearon porcentajes, por lo que se hicieron pruebas de hipótesis de comparación de proporciones para muestras independientes,${ }^{10}$ teniendo en cuenta niveles de confianza de $90 \mathrm{y}$ 95 por ciento. Esto con el fin de verificar si las diferencias entre los grupos y en los distintos periodos eran estadísticamente significativas. Por tanto, las hipótesis de referencia planteadas fueron:

- Hipótesis nula: $\mathrm{px}_{\mathrm{t}}^{\mathrm{i}}=\mathrm{px}_{\mathrm{t}+1}^{\mathrm{i}}$

- Hipótesis alternativa: $\mathrm{px}_{\mathrm{t}}^{\mathrm{i}}{ }^{1} \mathrm{px}_{\mathrm{t}+1}^{\mathrm{i}}$

Donde:

$p x_{\mathrm{t}}^{\mathrm{i}}$ es la proporción de hogares con la característica $x$ en la población $i$ para el periodo $t$.

$p x^{\mathrm{i}}{ }_{\mathrm{t}+1}$ es la proporción de hogares con la característica $x$ en la población $i$ para el siguiente periodo censal o intercensal.

Las fuentes de información empleadas en esta investigación fueron los Censos de Población y Vivienda de 1990, 2000 y 2010 (muestras de diez por ciento) en México, y la Encuesta Intercensal 2015. Estas fuentes permiten caracterizar distintas poblaciones de interés de manera transversal a partir de la obtención de indicadores sociodemográficos, sociolaborales y espaciales a niveles de viviendas, hogares e individuos a una escala más desagregada. Estos instrumentos permiten contrastar las estimaciones de los extranjeros con otras fuentes particulares como los registros administrativos de migración o estadísticas elaboradas por los países de origen. La

\footnotetext{
${ }^{9}$ Para un estudio más detallado la pregunta del lugar de nacimiento debería ser cruzada con otras como la nacionalidad de los padres o el tiempo de residencia del extranjero en el país, lo que permitiría identificar los extranjeros con y sin origen en el país.

${ }_{10}$ Este método contrasta un estadístico calculado con base en las proporciones comparadas con un estadístico obtenido por tablas de una distribución normal asumiendo distintos niveles de confianza y significancia.
} 
principal limitación de los Censos de Población y Vivienda es la falta de algunas preguntas relacionadas con la inmigración. Para Rodríguez (2016) es importante la inclusión de variables relacionadas como el año de llegada, situación de la ciudadanía actual, condición y causa de la migración. ${ }^{11}$

Una fortaleza de esta investigación fue el uso de la Encuesta Intercensal 2015, un referente pionero en el país, debido al gran tamaño de muestra. Ello permitió obtener indicadores confiables y actuales sobre los inmigrantes en el país. Las estimaciones estuvieron sujetas a los factores de expansión. Además, esta fuente permitió atender distintas demandas de información a nivel municipal. A diferencia de los anteriores Conteos de Población y Vivienda realizados en el país, la Encuesta Intercensal incluye la pregunta del lugar de nacimiento, así como la posesión de nacionalidad mexicana o no. ${ }^{12}$

\section{CARACTERÍSTICAS SOCIODEMOGRÁFICAS Y TERRITORIALES}

\section{Distribuciones absolutas y relativas por país de nacionalidad}

En 2015 la población extranjera residente en México representó 0.84 por ciento del total poblacional en el país. Es decir, un porcentaje menor en general, y porcentajes mínimos para las tres nacionalidades seleccionadas. Esos datos son congruentes con lo que reportan los censos mexicanos para los distintos decenios del siglo xx, en que en ningún caso la población total de extranjeros registrados llegó a 0.9 por ciento (Rodríguez, 2010: 60 y 107). En otras experiencias de la región, Estados Unidos y Argentina, por ejemplo, registraron en el último decenio alrededor de 15 y 4.4 por ciento de población extranjera residente en sus respectivos países, ${ }^{13}$ lo que ocurre en México es un proceso inmigratorio de menor volumen.

Como se ve en la Tabla 1a, Tabla 1b y Tabla 1c en los últimos 25 años el porcentaje mayor de extranjeros en el país corresponde a Estados Unidos con participaciones relativas que oscilan entre 55 y 80 por ciento aproximadamente; en segundo lugar, Guatemala con una participación cercana a cuatro por ciento a partir del 2000 , en términos absolutos y relativos muy distante de la población estadounidense. Honduras y El Salvador ocupa-

${ }^{11}$ Las causas de la inmigración fue una pregunta incluida en el cuestionario del Censo de Población y Vivienda del año 2000, los resultados indican un gran porcentaje de población que migró a México por motivos laborales (alrededor de 50 por ciento) y el resto distribuidos por motivos familiares, estudio o cuestión de refugio.

${ }_{12}$ El trabajo de Jiménez (2018) indica que en 2015 alrededor de 55 por ciento de los extranjeros en México no poseen la nacionalidad mexicana.

${ }_{13}$ Información proveniente del informe de inmigración laboral en América Latina elaborado por la Comisión Económica para el Desarrollo de América Latina (CEPAL, 2017) y la Organización Internacional del Trabajo (OIT) en el año 2017. 
rían el séptimo y noveno sitio con uno por ciento, respectivamente, en términos absolutos muy próximas entre sí, pero muy distantes de quienes se ubican en los dos primeros sitios de poblaciones extranjeras en México.

Colombia, Argentina, Cuba y Venezuela son otros colectivos de latinoamericanos posicionados en los diez primeros puestos. Es importante aclarar que el volumen de la población extranjera en México y su distribución relativa por nacionalidades de origen cambia cuando se discrimina la población estadounidense con ascendencia en México, es decir, con padres nacidos en el país.

Tabla 1a: Total de la población en México e inmigrantes internacionales residentes en México por país de nacimiento, 1990, 2000, 2010 y 2015

\begin{tabular}{|c|c|c|c|c|}
\hline \multirow{2}{*}{ País } & \multicolumn{4}{|c|}{ Población total } \\
\hline & 1990 & 2000 & 2010 & 2015 \\
\hline Estados Unidos & 194,619 & 343,591 & 739,918 & 739,168 \\
\hline Guatemala & 46,005 & 23,957 & 31,888 & 42,874 \\
\hline España & 24,873 & 21,024 & 20,727 & 22,646 \\
\hline Colombia & 4,964 & 6,215 & 12,832 & 18,735 \\
\hline Venezuela & 1,533 & 2,823 & 10,786 & 15,664 \\
\hline Argentina & 4,635 & 6,480 & 14,171 & 14,747 \\
\hline Honduras & 1,997 & 3,722 & 9,980 & 14,544 \\
\hline Cuba & 2,979 & 6,647 & 11,822 & 12,768 \\
\hline El Salvador & 5,215 & 5537 & 8,864 & 10,594 \\
\hline Canadá & 3,011 & 5,768 & 10,208 & 9,816 \\
\hline China $^{1}$ & 1,161 & 1,891 & 8,301 & 9,702 \\
\hline Francia & 4,195 & 5,723 & 8,533 & 8,625 \\
\hline Alemania & 4,499 & 5,595 & 7,033 & 6,400 \\
\hline Otro país & 41,138 & 53,644 & 73,899 & 81,622 \\
\hline Total & 340,824 & 492,617 & 968,147 & $1,007,063$ \\
\hline $\begin{array}{l}\text { Población total } \\
\text { en México }\end{array}$ & $81 ’ 249,645$ & $97^{\prime} 483,412$ & $112^{\prime} 336,538$ & $119^{\prime} 530,753$ \\
\hline$\%$ de Extranjeros & 0.42 & 0.53 & 0.86 & 0.84 \\
\hline
\end{tabular}

Nota: China incluye los códigos de China, Hong Kong, República de China o China Nacionalista; que son nombres alternos para Taiwán.

* Proporción estadísticamente no significativa comparada con el periodo inmediatamente anterior, a un nivel de confianza de 95 por ciento.

Fuente: elaboración propia con base en el INEGI, muestras de diez por ciento del XI Censo General de Población y Vivienda, 1990, XII Censo General de Población y Vivienda, 2000, y Censo de Población y Vivienda 2010, Encuesta Intercensal, 2015. 
Poblaciones guatemaltecas, hondureñas y salvadoreñas en México: perfiles propios y comparados ... / L.F. JIMÉNEZ y R. CASILLAS

En 2016, el Instituto Nacional de Estadística, Geografía e Informática (INEGI), en acuerdo con la Unidad Política Migratoria (UPM), estimó, con datos de 2015, que 70 por ciento de la población estadounidense tuvo origen en el país.

Con respecto a los cambios diacrónicos durante el periodo de análisis, con excepción de los españoles y guatemaltecos, todos los principales colectivos de inmigrantes del país tuvieron tasas de crecimiento elevadas entre 1990 y 2015.

Tabla 1b: Total de la población en México e inmigrantes internacionales residentes en México por país de nacimiento, 1990, 2000, 2010 y 2015

\begin{tabular}{|c|c|c|c|c|}
\hline \multirow{2}{*}{ País } & \multicolumn{4}{|c|}{ Distribución relativa } \\
\hline & 1990 & 2000 & 2010 & 2015 \\
\hline Estados Unidos & 57.10 & 69.75 & 76.43 & 73.40 \\
\hline Guatemala & 13.50 & 4.86 & 3.29 & 4.26 \\
\hline España & 7.30 & 4.27 & 2.14 & 2.25 \\
\hline Colombia & 1.46 & 1.26 & 1.33 & 1.86 \\
\hline Venezuela & 0.45 & 0.57 & 1.11 & 1.56 \\
\hline Argentina & 1.36 & 1.32 & 1.46 & $1.46^{*}$ \\
\hline Honduras & 0.59 & 0.76 & 1.03 & 1.44 \\
\hline Cuba & 0.87 & 1.35 & 1.22 & 1.27 \\
\hline El Salvador & 1.53 & 1.12 & 0.92 & 1.05 \\
\hline Canadá & 0.88 & 1.17 & 1.05 & 0.97 \\
\hline China $^{1}$ & 0.34 & 0.38 & 0.86 & 0.96 \\
\hline Francia & 1.23 & 1.16 & 0.88 & 0.86 \\
\hline Alemania & 1.32 & 1.14 & 0.73 & 0.64 \\
\hline Otro país & 12.07 & 10.89 & 7.63 & 8.10 \\
\hline Total & 100.0 & 100.0 & 100.0 & 100.0 \\
\hline $\begin{array}{l}\text { Población total } \\
\text { en México }\end{array}$ & $81^{\prime} 249,645$ & $97^{\prime} 483,412$ & $112^{\prime} 336,538$ & $119^{\prime} 530,753$ \\
\hline$\%$ de Extranjeros & 0.42 & 0.53 & 0.86 & 0.84 \\
\hline \multicolumn{5}{|c|}{$\begin{array}{l}\text { Nota: China incluye los códigos de China, Hong Kong, República de China o China Nacionalista; } \\
\text { que son nombres alternos para Taiwán. } \\
\text { * Proporción estadísticamente no significativa comparada con el periodo inmediatamente anterior, a } \\
\text { un nivel de confianza de } 95 \text { por ciento. } \\
\text { Fuente: elaboración propia con base en el INEGI, muestras de diez por ciento del XI Censo General } \\
\text { de Población y Vivienda, } 1990 \text {, XII Censo General de Población y Vivienda, 2000, y Censo de Po- } \\
\text { blación y Vivienda 2010, Encuesta Intercensal, } 2015 \text {. }\end{array}$} \\
\hline
\end{tabular}


Tabla 1c: Total de la población en México e inmigrantes internacionales residentes en México por país de nacimiento, 1990, 2000, 2010 y 2015

\begin{tabular}{|c|c|c|c|c|}
\hline \multirow[b]{2}{*}{ País } & \multicolumn{4}{|c|}{ Tasas de crecimiento } \\
\hline & $\begin{array}{l}1990 \\
2000\end{array}$ & $\begin{array}{l}2000 \\
2010\end{array}$ & $\begin{array}{l}2010 \\
2015\end{array}$ & $\begin{array}{l}1990 \\
2015\end{array}$ \\
\hline Estados Unidos & 76.55 & 115.35 & -0.10 & 279.80 \\
\hline Guatemala & -47.93 & 33.11 & 34.45 & -6.81 \\
\hline España & -15.47 & -1.41 & 9.26 & -8.95 \\
\hline Colombia & 25.20 & 106.47 & 46.00 & 277.42 \\
\hline Venezuela & 84.15 & 282.08 & 45.23 & 921.79 \\
\hline Argentina & 39.81 & 118.69 & 4.06 & 218.17 \\
\hline Honduras & 86.38 & 168.14 & 45.73 & 628.29 \\
\hline Cuba & 123.13 & 77.85 & 8.00 & 328.60 \\
\hline El Salvador & 6.17 & 60.09 & 19.52 & 103.14 \\
\hline Canadá & 91.56 & 76.98 & -3.84 & 226.00 \\
\hline China $^{1}$ & 62.88 & 338.97 & 16.88 & 735.66 \\
\hline Francia & 36.42 & 49.10 & 1.08 & 105.60 \\
\hline Alemania & 24.36 & 25.70 & -9.00 & 42.25 \\
\hline Otro país & 30.40 & 37.76 & 10.45 & 98.41 \\
\hline Total & 44.54 & 96.53 & 4.02 & 195.48 \\
\hline $\begin{array}{l}\text { Población total } \\
\text { en México }\end{array}$ & $81 ’ 249,645$ & $97^{\prime} 483,412$ & $112^{\prime} 336,538$ & $119^{\prime} 530,753$ \\
\hline$\%$ de Extranjeros & 0.42 & 0.53 & 0.86 & 0.84 \\
\hline
\end{tabular}

Nota: China incluye los códigos de China, Hong Kong, República de China o China Nacionalista; que son nombres alternos para Taiwán.

* Proporción estadísticamente no significativa comparada con el periodo inmediatamente anterior, a un nivel de confianza de 95 por ciento.

Fuente: elaboración propia con base en el INEGI, muestras de diez por ciento del XI Censo General de Población y Vivienda, 1990, XII Censo General de Población y Vivienda, 2000, y Censo de Población y Vivienda 2010, Encuesta Intercensal, 2015.

Destacan los casos de Venezuela y Honduras países que incrementaron en nueve y seis veces sus inmigrantes de 1990 comparados con los de 2015, respectivamente.

En el caso de Guatemala y El Salvador se obtuvo dinámicas de crecimiento muy distantes, mientras el primer país disminuyó en términos absolutos y relativos la presencia de inmigrantes en el país, el segundo tuvo un crecimiento moderado (por cada un salvadoreño en 1990 residía uno más en 2015). 
Algunas hipótesis relacionadas con estos casos particulares se centran en: i) la crisis emergente de Venezuela, que provocó una excesiva emigración; ii) el deterioro social y económico de Honduras ha incrementado sus tasas de emigración drásticamente; iii) En Guatemala la aparente disminución entre el periodo analizado, se encuentra mediada por el arribo y posterior retorno de guatemaltecos a México durante los años noventa. Castillo y Vásquez (2010) indican que entre 1991 y 1993 regresaron a Guatemala un gran número de inmigrantes quienes habían salido durante los años ochenta por la crisis civil que afrontó ese país; su regreso es producto de los acuerdos de paz.

Con la información proveniente de Censos de Población y Vivienda $(1990,2000$ y 2010) y la Encuesta Intercensal (2015), se observa un leve incremento de la población migrante del norte de Centroamérica (PMNC) asentada en el país, la cual pasa de 53,217 en el año 2000 a 68,012 en el año 2015 (Figura 1). Destaca que, en cada uno de estos eventos estadísticos, la población migrante proveniente de Guatemala constituye más de la mitad de los migrantes de esta región. En los años 1990 y 2000, los migrantes salvadoreños se ubican como el segundo grupo de migrantes provenientes de dicha región, pero a partir de 2010, ese lugar lo ocupan los provenientes de Honduras. En 1990, los inmigrantes del norte centroamericano constituían 61.15 por ciento de los inmigrantes latinoamericanos en México, pero la orientación cambia a partir del año 2000, dado que la mayoría provienen de otros países de la región. Debido a estos montos, las características sociodemográficas y sociolaborales analizadas corresponden a los migrantes centroamericanos en su conjunto comparados con el resto de las poblaciones latinoamericanas.

El incremento en el porcentaje de migrantes centroamericanos, a partir de 2010, posiblemente se deba a las condiciones sociales imperantes en los tres países de análisis (Martínez, O. 2016 y Martínez y Martínez, 2018). Según datos del Anuario Estadístico de América Latina y el Caribe, 2016, la tasa anual de desempleo abierto (en el ámbito urbano) (CEPAL, 2016) en 2015 fue de 2.8 en Guatemala y de 8.8 en Honduras; el último dato disponible para El Salvador corresponde al año 2014, y es de 6.7. Con datos de 2014 (Banco Mundial, 2017a), se observa que la tasa de homicidios intencionales más alta para estos tres países es la de Honduras (con 75 por cada 100 mil habitantes), seguida por la de El Salvador (64.2) y Guatemala (31.2). 
Figura 1: México: Población inmigrante del norte de Centroamérica y resto de Latinoamérica, 1990, 2000, 2010 y 2015

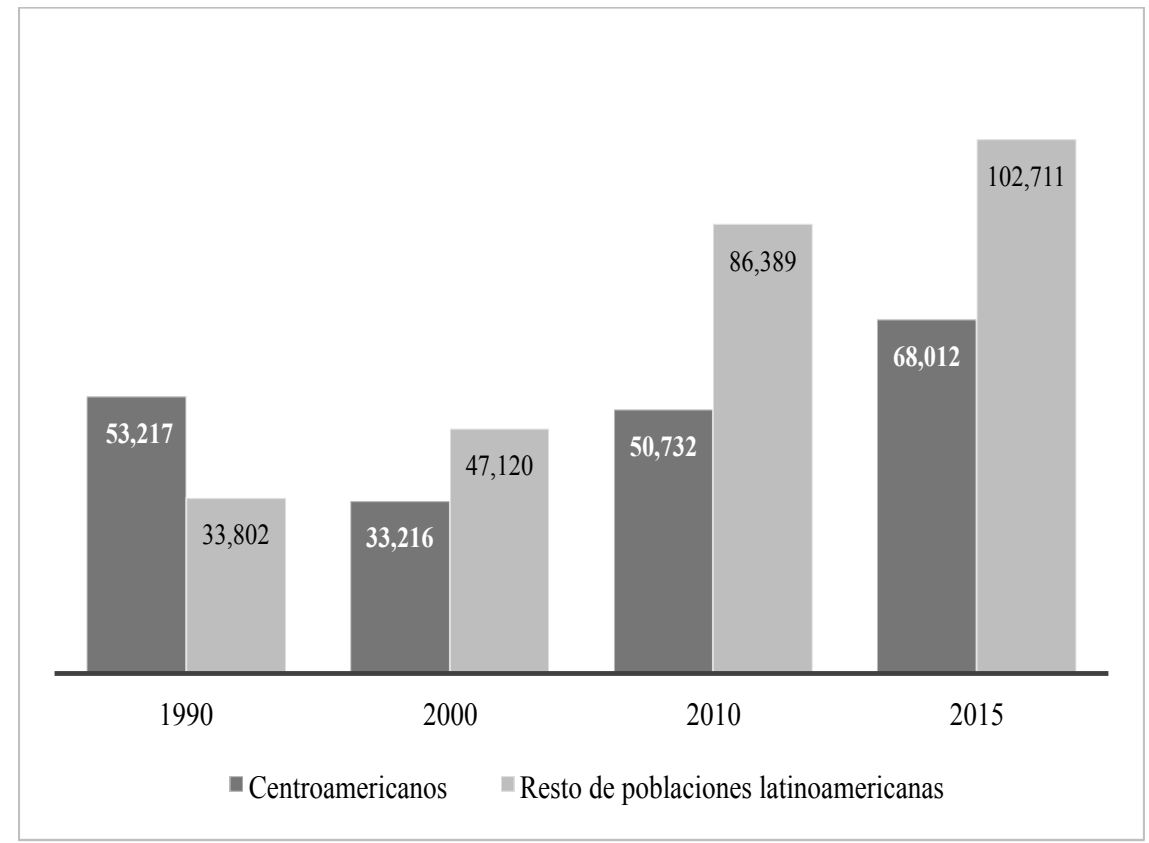

Fuente: elaboración propia con base en el INEGI, muestras de diez por ciento del XI Censo General de Población y Vivienda, 1990, XII Censo General de Población y Vivienda, 2000, y Censo de Población y Vivienda 2010, Encuesta Intercensal, 2015.

Naciones Unidas señala que cada vez más personas se ven obligadas a huir de la violencia en los países del norte de Centroamérica (Guatemala, Honduras y El Salvador), al tiempo que se ha visto un aumento en las solicitudes de asilo provenientes de estos países, de forma que, en los primeros cuatro meses de 2016, 11 mil personas requirieron la condición de refugiados principalmente en Estados Unidos y México (Naciones Unidas, 2016).

\section{Estructura por grupos de edad, sexo y región de residencia en México}

Por sexo, a partir del año 2000 se observan más mujeres que varones migrantes del norte centroamericano, es en el año 2010 cuando ocurre la mayor diferencia (55.4 contra 44.6 por ciento, respectivamente). La tendencia hacia la feminización es acorde con el resto de inmigrantes latinoamericanos. Según el reporte Mujeres en la Huida las mujeres y sus hijos huyen de los altos niveles de violencia, incluida la violencia basada en el género en Guatemala, El Salvador y Honduras, donde se reconoce control de grupos criminales, algunos de alcance transnacional (Martínez y Martínez, 2018). 
Las tasas de homicidios femeninos en estos países los colocan entre los diez primeros a nivel mundial. El Salvador es el que ocupa el primer lugar, seguido de Guatemala que está en tercero y Honduras en séptimo (ACNUR, 2015). Otros factores importantes para explicar la mayor presencia de mujeres inmigrantes son: el incremento del proceso de terciarización y la mayor participación femenina en el mercado de trabajo mexicano. Dicha argumentación se corroborará o no con algunos indicadores propios de la inserción laboral de la población inmigrante de interés (Tabla 2a, Tabla 2b y Tabla 2c).

Tabla 2a: Distribución porcentual de la población centroamericana comparada con otras poblaciones latinoamericanas residentes en México por sexo, grupo de edad y región de residencia, 1990-2015

\begin{tabular}{|c|c|c|c|c|}
\hline \multirow[t]{2}{*}{ Indicadores } & \multicolumn{4}{|c|}{$\begin{array}{l}\text { Población del norte } \\
\text { de Centroamérica }\end{array}$} \\
\hline & 1990 & 2000 & 2010 & 2015 \\
\hline \multicolumn{5}{|l|}{ Sexo } \\
\hline Hombres & 52.4 & 47.1 & 44.6 & 46.8 \\
\hline Mujeres & 47.6 & 52.9 & 55.4 & 53.2 \\
\hline Total & 100.0 & 100.0 & 100.0 & 100.0 \\
\hline \multicolumn{5}{|l|}{ Grupos de edad } \\
\hline Menores de 18 años & 35.0 & 12.6 & 14.2 & $14.14 *$ \\
\hline 19-29 años & 29.2 & 34.4 & 26.8 & $26.73 *$ \\
\hline 30-49 años & 25.7 & 37.9 & 42.2 & 41.7 \\
\hline 50 o más años & 9.9 & 14.7 & 16.8 & 17.4 \\
\hline No especificado & 0.2 & 0.5 & 0.0 & 0.1 \\
\hline Total & 100.0 & 100.0 & 100.0 & 100.0 \\
\hline \multicolumn{5}{|l|}{ Entidad de residencia } \\
\hline Chiapas & 56.7 & 48.2 & 52.1 & 49.2 \\
\hline Sur & 28.0 & 23.8 & 17.1 & 21.8 \\
\hline Centro & 11.4 & 19.6 & 18.3 & 14.8 \\
\hline Norte & 3.9 & 8.4 & 12.5 & 14.1 \\
\hline Total & 100.0 & 100.0 & 100.0 & 100.0 \\
\hline Población total & 53,217 & 33,216 & 50,732 & 68,012 \\
\hline
\end{tabular}

* Proporción estadísticamente no significativa comparada con el periodo inmediatamente anterior, a un nivel de confianza de 95 por ciento.

Fuente: Censos de Población y Vivienda 1990 y 2000; Muestra de diez por ciento del Censo de Población y Vivienda 2010; Encuesta Intercensal 2015. INEGI. 
En cuanto a la edad, con excepción de 1990, donde la mayoría de migrantes centroamericanos se ubica en el grupo de menos de 18 años de edad ( 35 por ciento), en el resto de los años analizados se observa que el mayor porcentaje de migrantes pertenecen al grupo de 30 a 49 años de edad y pese a lo que podría esperarse, el porcentaje de migrantes de $50 \mathrm{o}$ más años, es superior al de los menores de 18 años. Es decir, si bien se ha incrementado el porcentaje de migrantes centroamericanos de menos de 18 años (12.6 por ciento en 2000 contra 14.2 por ciento en 2010), en términos generales, es el grupo de edad con menor presencia.

Tabla 2b: Distribución porcentual de la población centroamericana comparada con otras poblaciones latinoamericanas residentes en México por sexo, grupo de edad y región de residencia, 1990-2015

\begin{tabular}{|c|c|c|c|c|}
\hline \multirow{2}{*}{ Indicadores } & \multicolumn{4}{|c|}{ Resto de población latinoamericana } \\
\hline & 1990 & 2000 & 2010 & 2015 \\
\hline \multicolumn{5}{|l|}{ Sexo } \\
\hline Hombres & 50.3 & 48.8 & 47.9 & $47.81^{*}$ \\
\hline Mujeres & 49.7 & 51.2 & 52.1 & $52.19 *$ \\
\hline Total & 100.0 & 100.0 & 100.0 & 100.0 \\
\hline \multicolumn{5}{|l|}{ Grupos de edad } \\
\hline Menores de 18 años & 14.5 & 12.3 & 11.6 & 10.7 \\
\hline 19-29 años & 27.0 & 22.7 & 18.3 & 18.7 \\
\hline 30-49 años & 39.2 & 41.3 & 45.5 & 45.2 \\
\hline 50 o más años & 19.1 & 23.4 & 24.5 & 25.4 \\
\hline No especificado & 0.2 & 0.3 & 0.0 & $0.03 *$ \\
\hline Total & 100.0 & 100.0 & 100.0 & 100.0 \\
\hline \multicolumn{5}{|l|}{ Entidad de residencia } \\
\hline Chiapas & 0.7 & $0.79 *$ & 1.7 & 1.0 \\
\hline Sur & 15.6 & 18.3 & 24.3 & 25.0 \\
\hline Centro & 69.3 & 65.0 & 57.3 & 57.8 \\
\hline Norte & 14.5 & 15.9 & 16.7 & 16.2 \\
\hline Total & 100.0 & 99 & 100.0 & 100.0 \\
\hline Población total & 33,734 & 47,120 & 86,389 & 102,711 \\
\hline
\end{tabular}


Poblaciones guatemaltecas, hondureñas y salvadoreñas en México: perfiles propios y comparados ... / L.F. JIMÉNEZ y R. CASILLAS

Tabla 2c: Distribución porcentual de la población centroamericana comparada con otras poblaciones latinoamericanas residentes en México por sexo, grupo de edad y región de residencia, 1990-2015

\begin{tabular}{|c|c|c|c|c|}
\hline \multirow{2}{*}{ Indicadores } & \multicolumn{4}{|c|}{ Total de latinoamericanos } \\
\hline & 1990 & 2000 & 2010 & 2015 \\
\hline \multicolumn{5}{|l|}{ Sexo } \\
\hline Hombres & 51.6 & 48.1 & 46.7 & 47.4 \\
\hline Mujeres & 48.4 & 51.9 & 53.3 & 52.6 \\
\hline Total & 100.0 & 100.0 & 100.0 & 100.0 \\
\hline \multicolumn{5}{|l|}{ Grupos de edad } \\
\hline Menores de 18 años & 27.0 & 12.4 & 12.6 & 12.1 \\
\hline 19-29 años & 28.3 & 27.5 & 21.5 & 21.9 \\
\hline 30-49 años & 31.0 & 39.9 & 44.3 & 43.8 \\
\hline 50 o más años & 13.5 & 19.8 & 21.7 & 22.2 \\
\hline No especificado & 0.2 & 0.4 & 0.0 & 0.0 \\
\hline Total & 100.0 & 100.0 & 100.0 & 100.0 \\
\hline \multicolumn{5}{|l|}{ Entidad de residencia } \\
\hline Chiapas & 35.0 & 20.4 & $20.4 *$ & $20.2^{*}$ \\
\hline Sur & 23.2 & 20.6 & 21.6 & 23.7 \\
\hline Centro & 33.8 & 46.2 & 42.9 & 40.7 \\
\hline Norte & 8.0 & 12.8 & 15.1 & 15.3 \\
\hline Total & 100.0 & 100.0 & 100.0 & 100.0 \\
\hline Población total & 86,951 & 80,336 & 137,121 & 170,723 \\
\hline
\end{tabular}

El anterior comportamiento varía relativamente con respecto al resto de la población latinoamericana. En los últimos 25 años, la tendencia muestra una mayor participación del grupo de 30 a 49 años de edad. No obstante, también ha tomado importancia la población con 50 años o más. En 2015, uno de cada cuatro inmigrantes de otros países latinoamericanos componía el grupo con mayor edad. La evidencia empírica indica una inmigración del norte de Centroamérica relativamente más joven con respecto al resto de población extranjera de la región.

Entre los datos que se pueden obtener con las fuentes señaladas está la identificación del lugar de residencia habitual (en este caso la entidad 
federativa) del migrante al momento de la entrevista. Para sintetizar los resultados, se agruparon según zona geográfica de residencia (Norte, Centro y Sur) con la excepción de Chiapas, entidad fronteriza con Guatemala.

Chiapas es la entidad donde se observa el mayor porcentaje de PMNC, aunque su proporción baja de 56.1 a 49.2 por ciento entre 1990 y 2015. Es un resultado esperado dada la vecindad geográfica con México, pero es muy probable que vuelva a subir en el siguiente registro por la migración de inicios de 2019. La otra mitad de inmigrantes centroamericanos en el país se ha diseminado por el resto de las entidades federativas. En los últimos años se observa una presencia relativa importante en las entidades del sur (Campeche, Guerrero, Morelos, Oaxaca, Puebla, Quintana Roo, Tabasco, Veracruz y Yucatán); los proyectos del gobierno actual de realizar obras de infraestructura en el sureste mexicano, en que se dice habrá participación de mano de obra centroamericana, podrán dar acogida a esta mano laboral del norte centroamericano, más la que llegue. En el caso de las zonas centro y norte del país se observan tendencias dispares entre sí en los últimos cinco lustros. Mientras en las entidades del centro (Aguascalientes, Colima, Ciudad de México, Guanajuato, Hidalgo, Jalisco, México, Michoacán, Nayarit, Querétaro, San Luis Potosí y Tlaxcala), la presencia de inmigrantes del norte centroamericano ha disminuido. En el caso de los estados del norte (Baja California, Baja California Sur, Coahuila, Chihuahua, Durango, Nuevo León, Sonora, Sinaloa, Tamaulipas y Zacatecas) se observa un leve incremento pasando de 3.9 en 1990 a 14.1 en 2015. Es posible que parte de quienes esperan respuesta a su petición de refugio en localidades norteñas incrementen el volumen centroamericano en esa parte del país en el futuro inmediato, pero por lo pronto no hay información oficial disponible.

En cuanto a la distribución del resto de la población latinoamericana por región de residencia, la mayoría de inmigrantes se concentra en el centro de la República. Este hecho era de esperarse dado que en esta zona se encuentra la Ciudad de México, un polo de atracción de inmigrantes de diferentes partes del mundo; además está Guadalajara, el segundo centro más poblado de México. Entre 1990 y 2015 la contribución relativa del resto de inmigrantes latinoamericanos en la zona centro pasó de 69.3 a 57.8 por ciento. La zona sur se caracteriza por ser la segunda región con mayor presencia de inmigrantes del resto de Latinoamérica en los últimos años. Las estimaciones indican que uno de cada cuatro inmigrantes provenientes de estos países vivía en una de las entidades del sur mexicano. Algunas de las ciudades con importante presencia de inmigrantes son Puebla y Cancún. 
En tercer lugar, se posicionan las entidades de la zona norte, con un leve incremento de este grupo de extranjeros (14.5 en 1990 y 16.2 en 2015).

\section{Condición de lengua indígena y características educativas}

Al tomar en cuenta las características sociodemográficas de los migrantes centroamericanos se observa que la condición de lengua indígena ofrece una aproximación para identificar a la población indígena. Según el Banco Mundial, Guatemala es uno de los países con mayor contribución relativa de población indígena sobre el total de la población (41 por ciento en 2002). En el caso de Honduras y El Salvador los indígenas contribuían a la población total con 7.2 por ciento y 0.02 por ciento en 2002 y 2007 , respectivamente. De 1990 a 2010 se evidencia una tendencia a la baja en la proporción de migrantes centroamericanos hablantes de lengua indígena: mientras en 1990, 49.3 por ciento de los migrantes cumplen con esta característica, para 2010 la proporción es de 15.3. A pesar de la disminución, es importante destacar que su presencia relativa ha sido mucho mayor comparada con el resto de población latinoamericana. Para este último grupo la población indígena en ningún caso ha superado más de dos por ciento del total de los inmigrantes.

Con el análisis de la variable condición de alfabetismo se observa que los migrantes provenientes de uno de los tres países de interés, de 15 años o más, cada vez presentan menores porcentajes de analfabetismo (El Salvador). Mientras en 1990, 23.8 por ciento no sabía leer y escribir, en el año 2000, 26.2 por ciento; para los años 2010 y 2015, sólo 17 por ciento de los migrantes del norte de Centroamérica presentan dicha condición. Estos datos encuentran correspondencia con los del Banco Mundial (2017b) y también dan cuenta sobre la selectividad de los migrantes: en 2015, 88 por ciento de la población de 15 años o más sabe leer y escribir en Honduras y El Salvador. Guatemala posee el porcentaje más bajo de alfabetismo con 79 por ciento. Al comparar la condición de alfabetismo con el resto de inmigrantes latinoamericanos, se observa que los inmigrantes del norte centroamericano presentaron en todos los años de análisis mayores tasas de analfabetismo comparados con los otros colectivos.

La condición de asistencia escolar en la PMNC de 6 a 14 años de edad, que comprende las edades para cursar la educación básica, muestra que en 1990 se encontró el porcentaje más alto de asistencia escolar. De acuerdo con esta fuente 64.7 por ciento de los migrantes del grupo de edad señalado asiste regularmente a un centro de enseñanza; el segundo porcentaje más alto se observa en 2015 (59.9 por ciento). Si se toma como parámetro este 
último porcentaje y se compara con el de 2010 (56.2 por ciento) y 2000 (46.5 por ciento), se puede hablar de que hubo un retroceso en el acceso a la enseñanza durante un periodo de más diez años. Por alguna razón, existe algún tipo de impedimento de estos niños migrantes para poder acceder a la escuela en México. En una posición contraria se observa una mayor integración socioeducativa de los niños nacidos en otros países latinoamericanos, dadas las altas tasas de asistencia escolar en los niveles básicos de educación durante los veinticinco años analizados. Dicho porcentaje oscila entre 93 y 96.7 por ciento.

Con respecto a los niveles de escolaridad importa hacer una acotación: las fuentes se analizan de forma independiente debido a que no es posible su comparabilidad, dado que cada evento censal presenta algunas diferencias específicas en la recolección de sus datos. Asimismo, se señala que el nivel máximo de estudios refiere al nivel de escolaridad (años o grados concluidos) alcanzado por la persona.

En términos generales para todos los eventos estadísticos analizados, la distribución por niveles de escolaridad indica comportamientos distantes entre los inmigrantes del norte centroamericano y el resto de latinoamericanos. Mientras el primer grupo se concentra en su mayoría en los niveles más bajos de educación, el segundo lo hace en los niveles con Licenciatura o más. Estas tendencias indican una clara selectividad de migrantes calificados latinoamericanos con excepción del grupo centroamericano de interés.

Al tomar en consideración lo anterior, en 1990 se observa que 44.7 de los migrantes del norte centroamericano de 15 años o más no alcanzó ningún nivel de escolaridad, seguidos por quienes cuentan con primaria (37.4 por ciento) y posteriormente con secundaria (6.6 por ciento). En el caso del resto de latinoamericanos, en este mismo año, 45.9 por ciento alcanzo licenciatura, seguido de preparatoria y secundaria con 19.5 y 13.3 por ciento, respectivamente.

Respecto al año 2000, 41.1 de los inmigrantes del norte centroamericano cuentan con educación primaria como nivel máximo de estudios les siguen quienes no tienen estudios (26.8 por ciento) y quienes cuentan con secundaria (10.6 por ciento). Los porcentajes de bachillerato, licenciatura y posgrado son menores a diez por ciento. Con relación a los inmigrantes de otros países latinoamericanos, el nivel máximo de estudios fue licenciatura con 48.5 por ciento, seguido de preparatoria ( 23.8 por ciento) y posgrado (12 por ciento) (Tabla 3a, Tabla 3b y Tabla 3c). 
Poblaciones guatemaltecas, hondureñas y salvadoreñas en México: perfiles propios y comparados ... / L.F. JIMÉNEZ y R. CASILLAS

Tabla 3a: Distribución porcentual de la población centroamericana comparada con otras poblaciones latinoamericanas residentes en México por condición de lengua indígena e indicadores de escolaridad, 1990-2015

\begin{tabular}{|c|c|c|c|c|}
\hline \multirow{2}{*}{ Indicadores } & \multicolumn{4}{|c|}{ Población del norte de Centroamérica } \\
\hline & 1990 & 2000 & 2010 & 2015 \\
\hline \multicolumn{5}{|l|}{ Condición de lengua indígena } \\
\hline Sí & 49.3 & 26.0 & 15.1 & $15.3^{*}$ \\
\hline No & 48.7 & 73.6 & 84.6 & $84.7 *$ \\
\hline No especificado & 2.0 & 0.4 & 0.3 & n.d. \\
\hline Total & 100.0 & 100.0 & 100.0 & 100.0 \\
\hline Población con 5 años o más & 52,000 & 32,444 & 49,626 & 66,101 \\
\hline \multicolumn{5}{|l|}{ Condición de alfabetismo } \\
\hline Sabe leer y escribir & 75.9 & 73.7 & 81.9 & 80.7 \\
\hline No sabe leer y escribir & 23.8 & 26.2 & 17.2 & $17.0^{*}$ \\
\hline No especificado & 0.4 & 0.2 & 1.0 & 2.3 \\
\hline Total & 100.0 & 100.0 & 100.0 & 100.0 \\
\hline Población con 5 años o más & 52,000 & 32,444 & 49,626 & 66,101 \\
\hline \multicolumn{5}{|l|}{ Condición de asistencia } \\
\hline Sí & 64.7 & 46.5 & 56.2 & 59.9 \\
\hline No & 33.9 & 52.2 & 43.2 & 40.1 \\
\hline No especificado & 1.4 & $1.3^{*}$ & 0.7 & 0.0 \\
\hline Total & 100.0 & 100.0 & 100.0 & 100.0 \\
\hline Población entre 5 y 14 años & 12,750 & 2,054 & 3,868 & 5,050 \\
\hline \multicolumn{5}{|l|}{ Nivel máximo de estudios } \\
\hline Sin escolaridad & 44.7 & 26.8 & 19.2 & 20.3 \\
\hline Primaria & 37.4 & 41.1 & 43.7 & 43.1 \\
\hline Secundaria & 6.6 & 10.6 & 16.0 & 16.4 \\
\hline Preparatoria & 3.8 & 8.9 & 9.9 & 11.2 \\
\hline Licenciatura & 6.2 & 9.2 & 9.5 & 7.0 \\
\hline Posgrado & 1.4 & 2.0 & 1.7 & 1.8 \\
\hline No especificado & 0.0 & 1.3 & 0.0 & n.d, \\
\hline Total & 100.0 & 100.0 & 100.0 & 100.0 \\
\hline Población con 15 años o más & 39,250 & 30,390 & 45,758 & 61,010 \\
\hline
\end{tabular}

A partir del Censo de 2010 las preguntas de lengua indígena, asistencia escolar y alfabetismo se preguntan a partir de los tres años. En esta investigación se conserva el punto fijo de años para mantener la comparabilidad. Se subraya la proporción cuando su coeficiente de variación se encuentra por encima de 15 por ciento, es decir, sin representatividad en la muestra.

* Proporción estadísticamente no significativa comparada con el periodo inmediatamente anterior, a un nivel de confianza de 95 por ciento.

Fuente: Censos de Población y Vivienda 1990 y 2000; Muestra de diez por ciento del Censo de Población y Vivienda 2010; Encuesta Intercensal 2015. INEGI. 
Tabla 3b: Distribución porcentual de la población centroamericana comparada con otras poblaciones latinoamericanas residentes en México por condición de lengua indígena e indicadores de escolaridad, 1990-2015

\begin{tabular}{|c|c|c|c|c|}
\hline \multirow{2}{*}{ Indicadores } & \multicolumn{4}{|c|}{ Resto de población latinoamericana } \\
\hline & 1990 & 2000 & 2010 & 2015 \\
\hline \multicolumn{5}{|l|}{ Condición de lengua indígena } \\
\hline Sí & 1.7 & $1.5^{*}$ & 1.4 & 1.2 \\
\hline No & 94.2 & 97.8 & 98.0 & 98.3 \\
\hline No especificado & 4.1 & 0.7 & $0.7 *$ & n.d. \\
\hline Total & 100.0 & 100.0 & 100.0 & 100.0 \\
\hline Población con 5 años o más & 32,992 & 45,869 & 84,795 & 100,570 \\
\hline \multicolumn{5}{|l|}{ Condición de alfabetismo ( } \\
\hline Sabe leer y escribir & 98.3 & 98.7 & 98.3 & $98.3 *$ \\
\hline No sabe leer y escribir & 1.5 & 1.2 & 0.6 & 0.8 \\
\hline No especificado & 0.2 & $0.2 *$ & 1.1 & 0.9 \\
\hline Total & 100.0 & 100.0 & 100.0 & 100.0 \\
\hline Población con 5 años o más & 32,992 & 45,869 & 84,795 & 100,570 \\
\hline \multicolumn{5}{|l|}{ Condición de asistencia } \\
\hline Sí & 93.4 & 93.0 & 94.0 & 96.7 \\
\hline No & 5.9 & 6.1 & 5.2 & 3.1 \\
\hline No especificado & 0.7 & 0.9 & 0.9 & 0.0 \\
\hline Total & 100.0 & 100.0 & 100.0 & 100.0 \\
\hline Población entre 5 y 14 años & 3,029 & 3,368 & 6,550 & 6,699 \\
\hline \multicolumn{5}{|l|}{ Nivel máximo de estudios } \\
\hline Sin escolaridad & 1.9 & 0.9 & 0.6 & 0.6 \\
\hline Primaria & 7.5 & 5.2 & 3.5 & 3.2 \\
\hline Secundaria & 13.3 & 8.5 & 6.0 & 7.4 \\
\hline Preparatoria & 19.5 & 23.8 & 20.7 & 19.7 \\
\hline Licenciatura & 45.9 & 48.5 & 55.1 & 52.3 \\
\hline Posgrado & 11.8 & 12.0 & 13.2 & 16.3 \\
\hline No especificado & 0.0 & 1.1 & 0.9 & n.d. \\
\hline Total & 100.0 & 100.0 & 100.0 & 100.0 \\
\hline Población con 15 años o más & 29,963 & 42,501 & 78,245 & 93,840 \\
\hline
\end{tabular}

A partir del Censo de 2010 las preguntas de lengua indígena, asistencia escolar y alfabetismo se preguntan a partir de los tres años. En esta investigación se conserva el punto fijo de años para mantener la comparabilidad. Se subraya la proporción cuando su coeficiente de variación se encuentra por encima de 15 por ciento, es decir, sin representatividad en la muestra.

* Proporción estadísticamente no significativa comparada con el periodo inmediatamente anterior, a un nivel de confianza de 95 por ciento.

Fuente: Censos de Población y Vivienda 1990 y 2000; Muestra de diez por ciento del Censo de Población y Vivienda 2010; Encuesta Intercensal 2015. INEGI. 
Poblaciones guatemaltecas, hondureñas y salvadoreñas en México: perfiles propios y comparados ... / L.F. JIMÉNEZ y R. CASILLAS

Tabla 3c: Distribución porcentual de la población centroamericana comparada con otras poblaciones latinoamericanas residentes en México por condición de lengua indígena e indicadores de escolaridad, 1990-2015

\begin{tabular}{|c|c|c|c|c|}
\hline \multirow{2}{*}{ Indicadores } & \multicolumn{4}{|c|}{ Total de latinoamericanos } \\
\hline & 1990 & 2000 & 2010 & 2015 \\
\hline \multicolumn{5}{|l|}{ Condición de lengua indígena } \\
\hline Sí & 30.8 & 11.7 & 8.3 & 6.8 \\
\hline No & 66.4 & 87.8 & 91.3 & 92.9 \\
\hline No especificado & 2.8 & 0.6 & 0.5 & n.d. \\
\hline Total & 100.0 & 100.0 & 100.0 & 100.0 \\
\hline Población con 5 años o más & 84,992 & 78,313 & 134,421 & 166,671 \\
\hline \multicolumn{5}{|l|}{ Condición de alfabetismo } \\
\hline Sabe leer y escribir & 74.4 & 88.3 & 92.2 & 91.3 \\
\hline No sabe leer y escribir & 23.4 & 11.5 & 6.7 & 7.2 \\
\hline No especificado & 2.3 & 0.2 & 1.0 & 1.5 \\
\hline Total & 100.0 & 100.0 & 100.0 & 100.0 \\
\hline Población con 5 años o más & 84,992 & 78,313 & 134,421 & 166,671 \\
\hline \multicolumn{5}{|l|}{ Condición de asistencia } \\
\hline Sí & 70.2 & 75.4 & 79.9 & $80.9^{*}$ \\
\hline No & 28.5 & 23.5 & 19.3 & $19.0^{*}$ \\
\hline No especificado & 1.3 & 1.1 & 0.8 & 0.0 \\
\hline Total & 100.0 & 100.0 & 100.0 & 100.0 \\
\hline Población entre 5 y 14 años & 15,779 & 5,422 & 10,418 & 11,749 \\
\hline \multicolumn{5}{|l|}{ Nivel máximo de estudios } \\
\hline Sin escolaridad & 26.2 & 11.7 & 7.5 & 8.4 \\
\hline Primaria & 24.5 & 20.2 & 18.3 & 18.9 \\
\hline Secundaria & 9.5 & 9.4 & 9.7 & 10.9 \\
\hline Preparatoria & 10.6 & 17.6 & 16.7 & 16.4 \\
\hline Licenciatura & 23.4 & 32.1 & 38.3 & 34.4 \\
\hline Posgrado & 5.9 & 7.8 & 8.9 & 10.6 \\
\hline No especificado & 0.0 & 1.2 & 0.6 & n.d. \\
\hline Total & 100.0 & 100.0 & 100.0 & 100.0 \\
\hline Población con 15 años o más & 69,213 & 72,891 & 124,003 & 154,850 \\
\hline
\end{tabular}

A partir del Censo de 2010 las preguntas de lengua indígena, asistencia escolar y alfabetismo se preguntan a partir de los tres años. En esta investigación se conserva el punto fijo de años para mantener la comparabilidad. Se subraya la proporción cuando su coeficiente de variación se encuentra por encima de 15 por ciento, es decir, sin representatividad en la muestra.

* Proporción estadísticamente no significativa comparada con el periodo inmediatamente anterior, a un nivel de confianza de 95 por ciento.

Fuente: Censos de Población y Vivienda 1990 y 2000; Muestra de diez por ciento del Censo de Población y Vivienda 2010; Encuesta Intercensal 2015. INEGI. 
En 2010, mientras 43.7 por ciento de los migrantes de 15 o más años tiene primaria completa, 19.2 por ciento no tiene estudios, la secundaria es el siguiente nivel máximo de estudios (16 por ciento), y bachillerato representa 11 por ciento. Al considerar al otro colectivo de inmigrantes latinoamericanos más de la mitad alcanzó una carrera profesional (55.1 por ciento), 20.7 por ciento figura con preparatoria y 13.2 por ciento con posgrado.

Finalmente, para $2015,59.8$ por ciento de los migrantes tienen educación básica (43.1 por ciento primaria y 16.4 por ciento secundaria), contra 20.3 por ciento que no tiene estudios. El porcentaje de quienes cuentan con bachillerato es de 11.2 por ciento. En el caso del resto de latinoamericanos, siete de cada diez inmigrantes tienen licenciatura ( 52.3 por ciento) o posgrado (16.3 por ciento). Los niveles de bachillerato y secundaria presentan una participación relativa modesta, 19.7 y 7.4 por ciento, respectivamente.

\section{Situación conyugal, fecundidad femenina y composición de los hogares}

Con excepción de 1990, cerca de dos terceras partes de la PMNC de 12 años o más son casados o están en unión libre. Es el año 2010 cuando se observa el porcentaje más alto de personas con dicha situación conyugal en el periodo con 70.4 por ciento. El siguiente grupo lo constituyen los solteros, con porcentajes que fluctúan entre 20.2 y 32.6 por ciento, aunque ni en éste ni para el grupo anterior se distinguen tendencias en los datos a lo largo del tiempo.

Finalmente, se destaca que la tendencia en los porcentajes de población alguna vez unida (separados o divorciados y viudos) ha aumentado levemente en los últimos años (5.1 por ciento en 1990 contra tres por ciento en 2010). La situación conyugal de los migrantes del norte centroamericano es uno de los indicadores más similar al caso del resto de latinoamericanos. En los últimos años de cada diez inmigrantes de estos países, aproximadamente seis están unidos, tres no unidos y uno alguna vez estuvo casado o en unión libre. Es probable que este cambio en la situación conyugal guarde relación con posibles nuevas uniones y las disoluciones de esas relaciones, ya sean matrimonios o uniones libres, ocurridas durante el periodo de residencia de la PMNC y el resto de los latinoamericanos en México.

Ligado a la variable anterior se presentan datos sobre hijos nacidos vivos de mujeres migrantes centroamericanas y el resto de latinoamericanas de 12 años o más (Tabla 4a, Tabla 4b y Tabla 4c). 
Poblaciones guatemaltecas, hondureñas y salvadoreñas en México: perfiles propios y comparados ... / L.F. JIMÉNEZ y R. CASILLAS

Tabla 4a: Distribución porcentual de la población centroamericana comparada con otras poblaciones latinoamericanas residentes en México por indicadores de composición de la familia, 1990-2015

\begin{tabular}{|c|c|c|c|c|}
\hline \multirow{2}{*}{ Indicadores } & \multicolumn{4}{|c|}{ Población del norte de Centroamérica } \\
\hline & 1990 & 2000 & 2010 & 2015 \\
\hline \multicolumn{5}{|l|}{ Tipo de hogar } \\
\hline Familiar & 87.4 & 85.6 & 93.5 & 92.5 \\
\hline No familiar & 10.6 & 13.9 & 5.9 & 7.5 \\
\hline No especificado & 2.0 & 0.5 & 0.6 & 0.0 \\
\hline Total & 100.0 & 100.0 & 100.0 & 100.0 \\
\hline Población total & 53,217 & 33,216 & 50,732 & 68,012 \\
\hline \multicolumn{5}{|l|}{ Número de hijos } \\
\hline Sin hijos & 35.1 & 21.6 & 19.0 & 18.3 \\
\hline 1 a 3 & 36.3 & 44.5 & 52.2 & 49.6 \\
\hline 4 o más & 28.6 & 32.4 & 27.2 & 29.7 \\
\hline No especificado & 0.0 & 1.5 & $1.6^{*}$ & 2.4 \\
\hline Total & 100.0 & 100.0 & 100.0 & 100.0 \\
\hline $\begin{array}{l}\text { Población femenina con } 12 \\
\text { años o más }\end{array}$ & 20,904 & 15,978 & 25,797 & 33,523 \\
\hline \multicolumn{5}{|l|}{ Situación conyugal } \\
\hline Unido & 61.3 & 69.8 & 70.4 & $70.0^{*}$ \\
\hline Alguna vez unido & 5.1 & 8.3 & 9.3 & 9.0 \\
\hline No unido & 32.6 & 21.6 & 20.2 & 20.9 \\
\hline No especificado & 1.0 & 0.3 & 0.2 & n.d. \\
\hline Total & 100.0 & 100.0 & 100.0 & 100.0 \\
\hline $\begin{array}{l}\text { Población con } 12 \text { años o } \\
\text { más }\end{array}$ & 44,133 & 31,111 & 47,042 & 62,954 \\
\hline
\end{tabular}

* Proporción estadísticamente no significativa comparada con el periodo inmediatamente anterior, a un nivel de confianza de 95 por ciento.

Fuente: Censos de Población y Vivienda 1990 y 2000; Muestra de diez por ciento del Censo de Población y Vivienda 2010; Encuesta Intercensal 2015. INEGI.

Al analizar la condición de hijos nacidos vivos se observa que, en 1990, seis de cada diez mujeres tenían al menos un hijo (36.3 por ciento tuvo de uno a tres y 28.6 por ciento, cuatro o más hijos). En 2000 esta proporción sube a ocho de cada diez (en porcentaje, las mujeres que tuvieron de uno a tres hijos representaron 44.5 por ciento), y dicha proporción se mantiene para 2010 y 2015, años en los que el porcentaje más alto sigue siendo el de las mujeres con uno a tres hijos nacidos vivos (52.2 y 49.6 por ciento, respectivamente). 
Tabla 4b: Distribución porcentual de la población centroamericana comparada con otras poblaciones latinoamericanas residentes en México por indicadores de composición de la familia, 1990-2015

\begin{tabular}{|c|c|c|c|c|}
\hline \multirow{2}{*}{ Indicadores } & \multicolumn{4}{|c|}{ Resto de población latinoamericana } \\
\hline & 1990 & 2000 & 2010 & 2015 \\
\hline \multicolumn{5}{|l|}{ Tipo de hogar } \\
\hline Familiar & 84.0 & 85.6 & 86.8 & 83.5 \\
\hline No familiar & 13.7 & $13.9 *$ & 12.3 & 16.5 \\
\hline No especificado & 2.3 & 0.5 & 0.9 & 0.0 \\
\hline Total & 100.0 & 100.0 & 100.0 & 100.0 \\
\hline Población total & 33,734 & 47,120 & 86,389 & 102,711 \\
\hline \multicolumn{5}{|l|}{ Número de hijos } \\
\hline Sin hijos & 37.4 & 34.5 & 33.2 & 36.9 \\
\hline 1 a 3 & 51.7 & 54.1 & 56.0 & 54.4 \\
\hline 4 o más & 10.9 & 9.7 & 8.3 & 6.0 \\
\hline No especificado & 0.0 & 1.7 & 2.6 & $2.7^{*}$ \\
\hline Total & 100.0 & 100.0 & 100.0 & 100.0 \\
\hline $\begin{array}{l}\text { Población femenina con } 12 \\
\text { años o más }\end{array}$ & 15,455 & 22,000 & 41,126 & 50,039 \\
\hline \multicolumn{5}{|l|}{ Situación conyugal } \\
\hline Unido & 60.1 & 63.2 & 65.7 & 63.3 \\
\hline Alguna vez unido & 8.0 & 10.1 & $9.8^{*}$ & 9.3 \\
\hline No unido & 30.9 & 26.4 & 24.2 & 27.2 \\
\hline No especificado & 1.0 & 0.4 & 0.3 & n.d. \\
\hline Total & 100.0 & 100.0 & 100.0 & 100.0 \\
\hline Población con 12 años o más & 31,038 & 43,563 & 80,292 & 96,217 \\
\hline
\end{tabular}

En cuanto al resto de latinoamericanos, en todos los años de análisis más de la mitad de las mujeres tuvo entre uno y tres hijos. También llama la atención que entre 1990-2015, aproximadamente una de cada tres mujeres no tuvo hijos. Este porcentaje fluctúa entre 33.2 y 37.4 por ciento. Con menores proporciones se encuentran las mujeres con más de tres hijos: en 1990 se observó el porcentaje más alto con 10.9 por ciento y en 2015 el más bajo con seis por ciento. 
Poblaciones guatemaltecas, hondureñas y salvadoreñas en México: perfiles propios y comparados ... / L.F. JIMÉNEZ y R. CASILLAS

Tabla 4c: Distribución porcentual de la población centroamericana comparada con otras poblaciones latinoamericanas residentes en México por indicadores de composición de la familia, 1990-2015

\begin{tabular}{|c|c|c|c|c|}
\hline \multirow{2}{*}{ Indicadores } & \multicolumn{4}{|c|}{ Total de latinoamericanos } \\
\hline & 1990 & 2000 & 2010 & 2015 \\
\hline \multicolumn{5}{|l|}{ Tipo de hogar } \\
\hline Familiar & 86.1 & 88.5 & 91.3 & 89.3 \\
\hline No familiar & 11.8 & 11.1 & 8.0 & 9.9 \\
\hline No especificado & 2.1 & 0.4 & 0.7 & 0.8 \\
\hline Total & 100.0 & 100.0 & 100.0 & 100.0 \\
\hline Población total & 86,951 & 80,336 & 137,121 & 170,723 \\
\hline \multicolumn{5}{|l|}{ Número de hijos } \\
\hline Sin hijos & 36.1 & 29.1 & 27.7 & 29.4 \\
\hline 1 a 3 & 42.9 & 50.1 & 54.6 & 52.5 \\
\hline 4 o más & 21.1 & 19.3 & 15.5 & $15.5^{*}$ \\
\hline No especificado & 0.0 & 1.6 & 2.2 & 2.6 \\
\hline Total & 100.0 & 100.0 & 100.0 & 100.0 \\
\hline $\begin{array}{l}\text { Población femenina con } 12 \text { años o } \\
\text { más }\end{array}$ & 36,359 & 37,978 & 66,923 & 83,562 \\
\hline \multicolumn{5}{|l|}{ Situación conyugal } \\
\hline Unido & 60.8 & 65.9 & 67.4 & 65.9 \\
\hline Alguna vez unido & 6.3 & 9.4 & 9.6 & 9.1 \\
\hline No unido & 31.9 & 24.4 & 22.7 & 24.7 \\
\hline No especificado & 1.0 & 0.3 & 0.2 & n.d. \\
\hline Total & 100.0 & 100.0 & 100.0 & 100.0 \\
\hline Población con 12 años o más & 75,171 & 74,674 & 127,334 & 159,171 \\
\hline
\end{tabular}

Como se observa en el indicador previo (situación conyugal), la mayoría de los migrantes del norte centroamericano y latinoamericanos están casados o tienen una unión libre, por lo que era previsible la captación de al menos un hijo nacido vivo entre las mujeres migrantes de 12 años o más y los porcentajes resultantes. Asimismo, como lo señala el reporte Mujeres en la Huida (ACNUR, 2015), se observa que las mujeres que huyen de la 
violencia de género en Centroamérica lo suelen hacer acompañadas de sus hijos.

\section{Características socio-laborales básicas}

A continuación se describen algunos indicadores de condición actividad e inserción laboral de los grupos de interés.

En general la actividad preponderante de los inmigrantes latinoamericanos en los últimos años (con excepción de 1990) es estar ocupado en alguna actividad del mercado de trabajo. En el caso de los inmigrantes centroamericanos los datos señalan que a partir del año 2000 más de la mitad se incorporó al mercado laboral. Este comportamiento es afín con el resto de latinoamericanos. Dicha participación económica es un indicio del fuerte peso que tiene la inmigración laboral latinoamericana en el país, así sea que su volumen poblacional sea menor.

En el segundo lugar de actividad para los dos colectivos de inmigrantes latinoamericanos analizados en esta investigación (con excepción de 1990) se ubica la población no económicamente activa (estudiantes, trabajadores no remunerados, jubilados, entre otros), aunque con porcentajes dispares a lo largo del periodo estudiado: para la PMNC van de 41.9 por ciento (en 2010) a 50.7 por ciento (en el año 1990); mientras que el resto de latinoamericanos oscila entre 38 y 59.6 por ciento. El predominio de esta condición de actividad en 1990 puede explicarse debido a los conflictos políticos del Cono Sur en los años setenta y los conflictos armados ocurridos en Centroamérica 1980-1990.

Con relación a los indicadores de estructura laboral los inmigrantes latinoamericanos cumplen con dos rasgos propios del mercado de trabajo en México en los últimos años: una mayor asalarización y la terciarización de las actividades económicas. (Ariza y Oliveira, 2014). En la variable tipo de empleo se observa un comportamiento similar tanto para la PMNC como para el resto de latinoamericanos. En todos los años del evento censal, seis de cada diez inmigrantes de estas dos subregiones ocuparon un empleo asalariado. En cuanto al autoempleo los inmigrantes de los países de interés señalaron levemente menores porcentajes comparados con los otros colectivos, siendo la brecha más pronunciada en 1990 (32.4 para los no centroamericanos contra 27.9).

Por otro lado, la distribución por rama de actividad económica fue la variable sociolaboral más heterogénea entre la PMNC en relación con los otros colectivos de la región. Los migrantes centroamericanos de interés señalan un incremento en la participación en actividades propias del sec- 
tor terciario y en particular en comercio, servicios personales $y$ distributivos. La población ocupada en esta rama ha triplicado su participación pasando de 14.1 en 1990 a 48.5 en 2015. La segunda rama de actividad de los centroamericanos (con excepción de 1990) han sido las actividades agricolas, aunque en los últimos años hubo una disminución importante (el cambio fue de 63.8 por ciento en 1990 a 22.3 por ciento en 2015). No obstante, en la actualidad la participación de estos inmigrantes en las actividades propias del sector primario es relativamente alta con respecto al resto de latinoamericanos. Con respecto a la participación en actividades industriales y de construcción, ésta ha ganado un leve protagonismo en los últimos años. En 1990, uno de cada diez centroamericanos se insertaba en esta rama, mientras en 2015 la razón es de dos de cada diez. Finalmente, el sector con una participación menos pronunciada son los servicios sociales, financieros y gobierno. Podría esperarse que en este último sector se incorporen los inmigrantes centroamericanos con mayores niveles de calificación.

En el caso de los inmigrantes del resto de Latinoamérica el ordenamiento por rama de actividad económica varía notoriamente con respecto al grupo centroamericano analizado. Dichos inmigrantes laborales se caracterizan ampliamente por posicionarse en una actividad propia del sector terciario. A partir de 2010 ocho de cada diez ocupados cumplen con este patrón. No obstante, a diferencia de los centroamericanos, la mayoría de inmigrantes del resto de la región (con excepción de 2010) figuran en actividades sociales, financieras y gobierno. En segundo lugar, señala una inserción laboral en comercio, servicios financieros y gobierno. Por otro lado, los inmigrantes del resto de América Latina en contraste con los inmigrantes centroamericanos han mostrado una disminución en actividades propias del sector secundario (20.5 por ciento en 1990 contra 14.7 por ciento en 2015). La última rama de inserción para este colectivo es señalada por las actividades agrícolas: los porcentajes no superar dos por ciento del total de ocupados.

Finalmente, un indicador más aproximado al nivel de calificación de los inmigrantes latinoamericanos en México es la distribución por categorías ocupacionales. En el caso de los centroamericanos se observa que la mayoría de ocupados desempeñan actividades manuales, a pesar de que dicha contribución ha disminuido alrededor de diez puntos porcentuales entre 1990 y 2010 (Tabla 5a, Tabla 5b y Tabla 5c). 
Tabla 5a: Distribución porcentual de la población centroamericana comparada con otras poblaciones latinoamericanas residentes en México por indicadores socioeconómicos, 1990-2015

\begin{tabular}{|c|c|c|c|c|}
\hline \multirow{2}{*}{ Indicadores } & \multicolumn{4}{|c|}{ Población del norte de Centroamérica } \\
\hline & 1990 & 2000 & 2010 & 2015 \\
\hline \multicolumn{5}{|l|}{ Condición de actividad } \\
\hline Ocupados & 46.3 & 53.6 & 57.4 & 56.5 \\
\hline Desocupado & 1.2 & 0.8 & 0.4 & 1.6 \\
\hline No económicamente activos & 50.7 & 45.2 & 41.9 & $41.9^{*}$ \\
\hline No especificado & 1.9 & 0.3 & $0.4^{*}$ & 0.0 \\
\hline Total & 100.0 & 100.0 & 100.0 & 100.0 \\
\hline Población con 12 años o más & 44,133 & 31,111 & 47,042 & 62,954 \\
\hline \multicolumn{5}{|l|}{ Tipo de empleo } \\
\hline Asalariado & 67.4 & 65.2 & 67.3 & 68.5 \\
\hline Auto-empleo & 27.9 & 31.3 & 30.2 & $29.9 *$ \\
\hline No especificado & 4.7 & 3.4 & 2.5 & 1.6 \\
\hline Total & 100.0 & 100.0 & 100.0 & 100.0 \\
\hline Población ocupada con 12 años o más & 20,437 & 16,939 & 27,185 & 35,537 \\
\hline \multicolumn{5}{|l|}{ Rama de actividad } \\
\hline Actividades agrícolas (primarias) & 63.8 & 40.4 & 25.6 & 22.3 \\
\hline Industria o construcción (secundario) & 11.7 & 16.5 & $16.4 *$ & 20.1 \\
\hline Comercio, servicios personales y distributivos & 14.1 & 31.8 & 48.9 & 48.5 \\
\hline Servicios sociales, financieros y gobierno & 7.7 & 9.4 & $9.2^{*}$ & 8.1 \\
\hline Terciario & 21.8 & 41.2 & 48.9 & 56.6 \\
\hline No especificado & 2.8 & 1.9 & 0.0 & 1.1 \\
\hline Total & 100.0 & 100.0 & 100.0 & 100.0 \\
\hline Población ocupada con 12 años o más & 20,437 & 16,939 & 27,185 & 35,537 \\
\hline \multicolumn{5}{|l|}{ Categoría ocupacional } \\
\hline Profesionista o directivo & 7.0 & 8.8 & $8.9^{*}$ & 5.2 \\
\hline No manual & 7.2 & 14.3 & 21.1 & 18.8 \\
\hline Sub total no manuales & 14.2 & 23.0 & 30.0 & 24.0 \\
\hline Manual & 85.8 & 77.0 & 70.4 & 75.4 \\
\hline Total & 100.0 & 100.0 & 100.0 & 99.0 \\
\hline Población ocupada con 12 años o más & 20,437 & 16,939 & 27,185 & 35,537 \\
\hline
\end{tabular}

* Proporción estadísticamente no significativa comparada con el periodo inmediatamente anterior, a un nivel de confianza de 95 por ciento.

Fuente: Censos de Población y Vivienda 1990 y 2000; Muestra de diez por ciento del Censo de Población y Vivienda 2010; Encuesta Intercensal 2015. INEGI. 
Poblaciones guatemaltecas, hondureñas y salvadoreñas en México: perfiles propios y comparados ... / L.F. JIMÉNEZ y R. CASILLAS

Tabla 5b: Distribución porcentual de la población centroamericana comparada con otras poblaciones latinoamericanas residentes en México por indicadores socioeconómicos, 1990-2015

\begin{tabular}{|c|c|c|c|c|}
\hline \multirow[t]{2}{*}{ Indicadores } & \multicolumn{4}{|c|}{ Resto de población latinoamericana } \\
\hline & 1990 & 2000 & 2010 & 2015 \\
\hline \multicolumn{5}{|l|}{ Condición de actividad } \\
\hline Ocupados & 43.7 & 53.2 & 60.6 & 58.8 \\
\hline Desocupado & 0.6 & 1.0 & 0.8 & 1.8 \\
\hline No económicamente activos & 54.6 & 45.4 & 38.0 & 39.4 \\
\hline No especificado & 1.1 & 0.3 & 0.7 & 0.0 \\
\hline Total & 100.0 & 100.0 & 100.0 & 100.0 \\
\hline Población con 12 años o más & 31,038 & 43,563 & 80,292 & 96,217 \\
\hline \multicolumn{5}{|l|}{ Tipo de empleo } \\
\hline Asalariado & 65.0 & $64.7 *$ & $65.0 *$ & 67.8 \\
\hline Auto-empleo & 32.4 & $32.7 *$ & $32.4 *$ & 31.2 \\
\hline No especificado & 2.7 & $2.5^{*}$ & $2.6^{*}$ & 1.0 \\
\hline Total & 100.0 & 100.0 & 100.0 & 100.0 \\
\hline Población ocupada con 12 años o más & 13,571 & 23,634 & 49,269 & 56,455 \\
\hline \multicolumn{5}{|l|}{ Rama de actividad } \\
\hline Actividades agrícolas (primarias) & 2.0 & 1.3 & $1.2^{*}$ & $1.2 *$ \\
\hline Industria o construcción (secundario) & 20.5 & 16.0 & 15.3 & 14.7 \\
\hline Comercio, servicios personales y distributivos & 30.1 & 37.0 & 47.7 & 35.7 \\
\hline Servicios sociales, financieros y gobierno & 43.2 & 41.6 & 35.8 & 45.6 \\
\hline Terciario & 73.3 & 78.5 & 83.5 & 81.3 \\
\hline No especificado & 4.2 & $4.1 *$ & 0.0 & 2.7 \\
\hline Total & 100.0 & 100.0 & 100.0 & 100.0 \\
\hline Población ocupada con 12 años o más & 13,571 & 23,634 & 49,269 & 56,455 \\
\hline \multicolumn{5}{|l|}{ Categoría ocupacional } \\
\hline Profesionista o directivo & 52.9 & 51.4 & 44.2 & 48.8 \\
\hline No manual & 31.8 & 33.4 & 40.0 & 34.8 \\
\hline Sub total no manuales & 84.7 & 84.8 & 84.1 & 83.6 \\
\hline Manual & 15.3 & 15.2 & 14.7 & 15.4 \\
\hline Total & 100.0 & 100.0 & 99.0 & 99.0 \\
\hline Población ocupada con 12 años o más & 13,571 & 23,634 & 49,269 & 56,455 \\
\hline
\end{tabular}

* Proporción estadísticamente no significativa comparada con el periodo inmediatamente anterior, a un nivel de confianza de 95 por ciento.

Fuente: Censos de Población y Vivienda 1990 y 2000; Muestra de diez por ciento del Censo de Población y Vivienda 2010; Encuesta Intercensal 2015. INEGI. 
Tabla 5c: Distribución porcentual de la población centroamericana comparada con otras poblaciones latinoamericanas residentes en México por indicadores socioeconómicos, 1990-2015

\begin{tabular}{|c|c|c|c|c|}
\hline \multirow{2}{*}{ Indicadores } & \multicolumn{4}{|c|}{ Total de latinoamericanos } \\
\hline & 1990 & 2000 & 2010 & 2015 \\
\hline \multicolumn{5}{|l|}{ Condición de actividad } \\
\hline Ocupados & 45.2 & 53.4 & 59.4 & 57.9 \\
\hline Desocupado & 0.9 & $0.9^{*}$ & 0.6 & 1.7 \\
\hline No económicamente activos & 52.3 & 45.3 & 39.4 & 40.4 \\
\hline No especificado & 1.6 & 0.3 & 0.6 & 0.0 \\
\hline Total & 100.0 & 100.0 & 100.0 & 100.0 \\
\hline Población con 12 años o más & 75,171 & 74,674 & 127,334 & 159,171 \\
\hline \multicolumn{5}{|l|}{ Tipo de empleo } \\
\hline Asalariado & 66.4 & 65.0 & 65.8 & 68.1 \\
\hline Auto-empleo & 29.7 & 32.1 & 31.6 & 30.7 \\
\hline No especificado & 3.9 & 2.9 & 2.6 & 1.2 \\
\hline Total & 100.0 & 100.0 & 100.0 & 100.0 \\
\hline Población ocupada con 12 años o más & 34,008 & 40,573 & 76,454 & 91,992 \\
\hline \multicolumn{5}{|l|}{ Rama de actividad } \\
\hline Actividades agrícolas (primarias) & 39.1 & 17.7 & 10.1 & 9.4 \\
\hline Industria o construcción (secundario) & 15.2 & 16.2 & 15.7 & 16.8 \\
\hline Comercio, servicios personales y distributivos & 20.5 & 34.8 & 48.1 & 40.7 \\
\hline Servicios sociales, financieros y gobierno & 21.8 & 28.1 & 26.1 & 31.1 \\
\hline Terciario & 42.3 & 62.9 & 74.2 & 71.8 \\
\hline No especificado & 3.3 & $3.2 *$ & 0.0 & 2.1 \\
\hline Total & 100.0 & 100.0 & 100.0 & 100.0 \\
\hline Población ocupada con 12 años o más & 34,008 & 40,573 & 76,454 & 91,992 \\
\hline \multicolumn{5}{|l|}{ Categoría ocupacional } \\
\hline Profesionista o directivo & 25.4 & 33.5 & 31.3 & 31.9 \\
\hline No manual & 17.0 & 25.4 & 33.3 & 28.6 \\
\hline Sub total no manuales & 42.5 & 58.9 & 64.6 & 60.5 \\
\hline Manual & 57.5 & 41.1 & 34.5 & 38.6 \\
\hline Total & 100.0 & 100.0 & 99.0 & 99.0 \\
\hline Población ocupada con 12 años o más & 34,008 & 40,573 & 76,454 & 91,992 \\
\hline
\end{tabular}

* Proporción estadísticamente no significativa comparada con el periodo inmediatamente anterior, a un nivel de confianza de 95 por ciento.

Fuente: Censos de Población y Vivienda 1990 y 2000; Muestra de diez por ciento del Censo de Población y Vivienda 2010; Encuesta Intercensal 2015. INEGI. 
Se pasó de 85.8 por ciento en el primer evento censal analizado a 75.4 en la estimación de la Encuesta del 2015. Por otro lado, afín con los bajos niveles de escolaridad y la baja participación en actividades terciarias altas (servicios sociales, financieros y de gobierno), los inmigrantes centroamericanos que se desempeñan en actividades no manuales en su mayoría lo hacen en puestos diferentes al de profesionistas o directivos.

La situación cambia cuando se analiza al resto de inmigrantes latinoamericanos. La mayoría se posiciona en actividades manuales y en particular en puestos de alta dirección, aunque dicha contribución disminuyó entre 1990-2010 y muestra un leve incremente en los últimos cinco años (52.9 en 1990, 51.4 en 2000, 44.2 en 2010 contra 48.8 en 2015). El segundo lugar lo constituyen los inmigrantes que realizan actividades manuales de calificación media o baja. Estos pesos relativos fluctúan entre 31.8 y 40 por ciento. Contrario a los centroamericanos, el resto de extranjeros provenientes de América Latina han tenido una contribución relativa baja en actividades manuales. Este resultado se puede relacionar con el indicador previo, dado que las actividades agrícolas, industriales y de construcción demandan regularmente una mano de obra manual.

\section{REFLEXIONES FINALES}

A partir de los datos seleccionados para este análisis, de 1990 y en particular a partir de este siglo XXI, la presencia de PMNC en México se ha ido dispersando a lo largo del territorio nacional, pero a la vez su peso relativo frente a otras nacionalidades, y en particular los latinoamericanos, ha disminuido. La presencia atomizada, aunque los volúmenes relativamente mayores se encuentren en las fronteras, puede tener diversas explicaciones. Históricamente, al menos en la frontera sur de México, desde tiempos lejanos ha sido lugar de destino de flujos motivados por razones políticas, sociales y económicas, aunque ello no ha desembocado en ningún momento en un crecimiento desproporcionado de ninguna de las tres nacionalidades centroamericanas de interés. Otra posible puede responder a exploraciones de nuevas rutas migratorias, hasta la decisión de algunos de quedarse a radicar en México al encontrar trabajo, o bien ante la imposibilidad de cruzar la frontera de Estados Unidos. La adaptación a un país con el que se comparte idioma, tradiciones y rasgos culturales, también es un factor que incide en la decisión de algunos por establecerse en México. Al considerar los datos del Censo General de Población y Vivienda 1990 en contraste con los de la Encuesta Intercensal de 2015 también se observa claramente 
que después del sur del país (más de Chiapas), la segunda concentración de migrantes centroamericanos se encuentra en el centro del país.

La decisión de quedarse en México posiblemente también esté relacionada con la calidad de vida (educación, salud, alimentación). Por ejemplo, en el caso de la educación guarda correspondencia con el dato de que más de la mitad de los niños migrantes centroamericanos de 6 a 14 años asiste regularmente a la escuela, según los resultados de las fuentes estadísticas analizadas. Desde otra óptica, a pesar de que en esas edades la educación debiera estar garantizada para todas las niñas y niños, un porcentaje importante de ellos no asiste. En el caso del resto latinoamericanos se observó una alta integración socioeducativa de estos inmigrantes extranjeros.

Otra de las características que resalta de este breve perfil es que, como señala la Organización de Naciones Unidas, se observa una transición en el tipo o características de la población centroamericana migrante. Mientras que en 1990 se observa un componente importante de migrantes por motivos económicos (considerando los porcentajes de hablantes de lengua indígena y analfabetismo), para 2010 y 2015 es más probable que quienes migren tengan entre sus principales motivos el de seguridad. Esta reflexión se refuerza con los datos de la estructura por edad y sexo donde se observa un número creciente de migrantes menores de 18 años, aunque sin precisar si transitan en compañía de un familiar o no acompañados (CNDH, 2016). Las niñas, niños y adolescentes migrantes centroamericanos se enfrentan en sus países de origen a múltiples violencias, tanto dentro de sus hogares como en sus comunidades. La población de Honduras es quien en mayor medida está huyendo de la violencia e inseguridad: 59.5 por ciento de las niñas, niños y adolescentes (NNA) hondureños son migrantes por este motivo; en el caso de los salvadoreños el porcentaje es de 40 por ciento y entre los guatemaltecos, 33.3 por ciento (Camargo, 2014; Martínez 2016; Martínez y Martínez, 2018).

Las mujeres son otro grupo vulnerable ante la situación de violencia que se vive en esos países de Centroamérica. El caso de Guatemala sirve para analizar por qué desde el censo de 1990 se observa una mayor cantidad de mujeres en relación con los varones migrantes. En efecto, en Guatemala, desde los años 1960, se observaron conflictos político-militares que generaron olas migratorias, principalmente provenientes de regiones inaccesibles del altiplano guatemalteco hacia el sur de México, con una creciente participación de mujeres (García Sánchez y Valdés Rodas, 2002). En años recientes, el problema entre pandillas, maras, la acción gubernamental en contra de ellas y la intervención de grupos vinculados al narcotráfico, junto 
con la creciente violencia hacia las mujeres, ha obligado a mujeres a seguir migrando solas o acompañadas por sus hijos; en el análisis correspondiente se observó que más de 60 por ciento de las mujeres migrantes centroamericanas de 12 o más años tenían al menos un hijo nacido vivo. No obstante, esto no significa necesariamente que migren con ellos, aunque hay fuertes evidencias de las acciones de maras en contra de las NNA (Martínez, 2010 y 2016).

Independientemente del tiempo de su estancia en México, los migrantes centroamericanos seleccionados, principalmente los varones, aunque con mayor participación femenina en años recientes, trabajan. Por su naturaleza, la información censal no permite precisar cuántos de éstos son trabajadores agrícolas, de aquellos que tienen intención seguir una ruta migratoria que los lleve rumbo a Estados Unidos (para tales propósitos existen otros instrumentos estadísticos que no son relacionables con la fuente censal). Es importante analizar, así sea en otro momento, el dato que señala la presencia de migrantes más allá de los estados fronterizos del sur, y su incremento en otros estados del centro y norte mexicanos.

Los datos aquí presentados corresponden con la población que fue censada en territorio nacional. Es decir, que un número importante de niños migrantes no acompañados, adultos y familias que se encuentran en tránsito rumbo a Estados Unidos no es contabilizado. Por tanto, estas cifras corresponden en gran parte a aquellos migrantes que por diversas circunstancias se han establecido en México de manera temporal al menos.

Aunado a las condiciones socioeconómicas, de violencia y falta de oportunidades en los países de origen, se suman los desastres naturales que en últimos años han afectado la región centroamericana, sobre todo en aquellas zonas de mayor vulnerabilidad a eventos meteorológicos (Programa Mundial de Alimentos, 2017). Esto ha ocasionado que en mayor medida la población se vea en la necesidad de buscar un espacio y fuentes de subsistencia alternos, aunque cabe aclarar que las fuentes disponibles documentan migraciones directas en los países del norte centroamericano de naturaleza interna, regionales y dentro del Istmo centroamericano, pero no necesaria ni directamente al norte continental.

A pesar de programas que buscan proteger a migrantes centroamericanos de la deportación y permitirles trabajar en Estados Unidos, como el Estatus de Protección Temporal (TPS, por sus siglas en inglés), éstos terminaron su vigencia en el primer trimestre de 2018 (Lesser y Batalova, 2017) y al momento de escribir este texto aún no se sabe con certeza qué resultado habrá para las poblaciones involucradas. Por lo anterior, se puede pensar 
en que los flujos de migrantes documentados o indocumentados se podrían ver seriamente afectados, en especial por los proyectos puestos en marcha y otros planeados por Estados Unidos para frenar la inmigración y reducir la ya existente en territorio estadounidense. Si ello llega a ocurrir, sería la primera vez que, desde su puesta en práctica con la firma de paz, desarme y democracia en Centroamérica, no fueran renovados e incrementados en cobertura numérica los permisos de estadía mencionados. Esa situación potencial no ocasionará que un mayor número de centroamericano deje de salir de su país ante las condiciones poco favorables para el tránsito por México y estadía en Estados Unidos, como se observa con el crecimiento inusual del flujo migratorio en los primeros meses de 2019, y que dio lugar a medidas extraordinarias de contención migratoria en la frontera sur de México. Se puede pensar en la posibilidad de que el número de migrantes del norte centroamericano en México se incremente si es que los gobiernos de los lugares de origen, tránsito y destino no les ofrecen alguna otra alternativa, pero de ello nos ocuparemos en otro texto y momento.

De octubre de 2018 a inicios de 2019 se presentó un crecimiento extraordinario de migrantes indocumentados en tránsito por México, oriundos principalmente del norte centroamericano. Hubo varias caravanas multinacionales que partieron de distintos sitios de Centroamérica y que se engrosaron más debido a dos razones de manera central: i) las declaraciones iniciales del gobierno entrante de México, de otorgar visas humanitarias de manera amplia y ii) el inicio de 2019 en que, como cada año, se caracteriza por el aumento del flujo migratorio laboral.

La reacción del gobierno estadounidense, ante la llegada intempestiva de miles de solicitantes de refugio, fue de menos a más, hasta llegar a amenazar con aplicar aranceles comerciales a México si éste no detenía el flujo de referencia. Los acuerdos de junio entre los gobiernos de Estados Unidos y México, en síntesis, fueron: la aplicación de medidas extraordinarias para la contención migratoria en la frontera sur de México y que quienes habiendo llegado hasta la frontera mexicana con Estados Unidos y hubieran gestionado su solicitud de refugio, aguardaran la respuesta en territorio mexicano.

Ambas cosas se han cumplido, pero, para efectos de este análisis, es pertinentes hacer las siguientes puntualizaciones: i) hasta el momento de escribir la versión final (septiembre de 2019), no hay información estadística disponible para caracterizar sociolaboralmente la población "estacionada" en México; ii) el gobierno mexicano ha anunciado la realización de magnas obras de infraestructura (redes ferroviarias y construcción de una 
planta procesadora de petróleo, principalmente) y plantar un millón de árboles, todo en el sureste mexicano. Para esas obras se considera la participación masiva de mano de obra, incluyendo la centroamericana que, por lo dicho en este análisis y suponiendo que los flujos recientes cuentan con un perfil laboral similar, bien pueden participar en las obras de referencia (es una posibilidad, no una certeza); y iii) se tiene noticia de que, quienes esperan la respuesta a su solicitud de refugio, son reubicados de localidades cercanas a Estados Unidos a localidades chiapanecas. No hay información oficial de cuánta de esa población solicitante será reubicada y dónde, pero es posible que ello implique una mayor presencia de oriundos del norte centroamericano en el sureste mexicano por tiempo indefinido. Quizá el Censo de Población de 2020 nos provea de nuevos elementos estadísticos para no sólo hablar de cifras, sino para ver si hay cambios significativos en el perfil sociolaboral de la población centroamericana en México, objeto de análisis en el presente texto.

\section{REFERENCIAS BIBLIOGRÁFICAS}

ACNUR, 2015, Mujeres en la Huida: relatos de primera mano de refugiadas que huyen de El Salvador, Guatemala, Honduras y México. Alto Comisionado de las Naciones Unidas para los Refugiados. Consultado el 31/05/2017. Disponible en http://www.acnur.org/fileadmin/scripts/doc.php?file=fileadmin/Documentos/Publicaciones/2016/10298

Aguayo, Sergio, 1985, El éxodo centroamericano. Consecuencias de un conflicto. México: Secretaría de Educación Pública, Consejo Nacional de Fomento Educativo

Ariza, Marina y Oliveira, O., 2014, “Terciarización de la mano de obra y protección laboral de la población asalariada en México", en Revista Realidad datos y espacio, vol. 2, núm. 5, pp. 34-47. Consultado el 9/02/2018. Disponible en https:// www.inegi.org.mx/rde/2014/05/08/terciarizacion-de-la-mano-de-obra-y-proteccion-laboral-de-la-poblacion-asalariada-en-mexico-2013/

Banco Mundial, 2015, Latinoamérica Indígena en el siglo XXI, Grupo Banco Mundial, Washington, D.C. Estados Unidos, Disponible en http://documents.worldbank. org/curated/en/541651467999959129/pdf/98544-WPP148348-Box394854B-PUBLIC-Latinoamerica-indigena-SPANISH.pdf

Banco Mundial, 2017a, Intentional homicides (per 100,000 inhabitanst). Interactive consultation of the free acces of the World Bank. Consultado el 31/05/2017. Disponible en http://datos.bancomundial.org/

Banco Mundial, 2017b, Literacy rate, total adults. Consulta interactiva de los Datos de libre acceso del Banco Mundial. Consultado el 31/05/2017. Disponible en http://datos.bancomundial.org/

Camargo, A., 2014, Arrancados de raíz. Causas que originan el desplazamiento transfronterizo de niños, niñas y adolescentes no acompañados y/o separados de 
Centroamérica y su necesidad de protección internacional. México: Oficina del Alto Comisionado de las Naciones Unidas para los Refugiados (ACNUR)-México. Consultado el 2/06/2017. Disponible en http://www.acnur.org/fileadmin/ scripts/doc.php?file=fileadmin/Documentos/Publicaciones/2014/9829

Canales, A. y Rojas, M., 2017, Panorama de la migración internacional en México y Centroamérica. Serie 124. Población y Desarrollo. CEPAL Y OIM. Consultado el 20/06/2019. Disponible en https://repositorio.cepal.org/bitstream/handle/11362/43697/1/S1800554_es.pdf

Castillo, M. y Vásquez, M., 2010, "Los inmigrantes guatemaltecos en México, Antecedentes históricos y situación actual", en Rodríguez, E. (ed.) Extranjeros en México, continuidades y nuevas aproximaciones. Instituto Nacional de Migración, Ciudad de México, pp. 237: 273.

CEPAL, 2016, Anuario Estadístico de América Latina y el Caribe 2016, Comisión Económica para América Latina y el Caribe. Consultado el 31/05/2017. Disponible en http://interwp.cepal.org/anuario_estadistico/Anuario_2016/es/index.asp

CEPAL, 2017, Panorama social de América Latina, Comisión Económica para América Latina y el Caribe, Santiago de Chile, Chile. Consultado el 2/06/2017) Disponible en Cepalstat.http://estadisticas.cepal.org/cepalstat/web_cepalstat/Portada.asp

CNDH, 2016, Informe sobre la problemática de niñas, niños y adolescentes centroamericanos en contexto de migración internacional no acompañados en su tránsito por México, y con necesidades de protección internacional. Comisión Nacional de los Derechos Humanos (6 de junio de 2017), Disponible en http:// www.cndh.org.mx/sites/all/doc/Informes/Especiales/Informe_NNACMNA.pdf

Dachary, A. A. C., 1990, Migraciones en la frontera México-Belice. Chetumal: Centro de Investigaciones de Quintana Roo.

Gandini, L., 2015, ¿Escapando de la crisis? Un análisis comparativo de la migración Argentina en México y España, UNAM, Cuernavaca, México.

García Sánchez, E. E., y Valdés Rodas, H. J., 2002, Informes Nacionales sobre migración internacional en países de Centroamérica. Taller de capacitación para el análisis de información censal sobre migración internacional en América Central. Serie Seminarios y Conferencias núm. 24, pp. 117-156. Guatemala. Centro Latinoamericano y Caribeño de Demografía (Celade). Consultado el 2/06/2017, Disponible en http://www.cepal.org/publicaciones/xml/9/11699/lcl1764_Guatemala.pdf

González, H., 2014, Se quedan en México para vivir mejor. o sobrevivir. Periódico Excélsior. La ruta de los migrantes. Consultado el 27/07/2014. Disponible en https://www.excelsior.com.mx/nacional/2014/07/27/973053

Grollova, Daniela, 1984, “Trabajo forzado en Guatemala, bracerismo guatemalteco en Chiapas”, en Cuicuilco. año 4, núm. 12, México, Escuela Nacional de Antropología e Historia, pp. 5-10. 
Poblaciones guatemaltecas, hondureñas y salvadoreñas en México: perfiles propios y comparados ... / L.F. JIMÉNEZ y R. CASILLAS

Helbig, Carlos, 1964, El Soconusco y su zona cafetalera en Chiapas. Tuxtla Gutiérrez: Instituto de Ciencias y Artes de Chiapas.

INEGI, 1990, XI Censo de Población y Vivienda 1990, Instituto Nacional de Estadística y Geografía, Aguascalientes.

INEGI, 2000, XII Censo de Población y Vivienda 2000, Instituto Nacional de Estadística y Geografía, Aguascalientes.

INEGI, 2010, XIII Censo de Población y Vivienda 2010, Instituto Nacional de Estadística y Geografía, Aguascalientes.

INEGI, 2015, Encuesta Intercensal 2015. Síntesis metodológica y conceptual Aguascalientes. Consultado el 23/05/2019. Disponible en http://internet.contenidos.inegi.org.mx/contenidos/Productos/prod_serv/contenidos/espanol/bvinegi/ productos/nueva_estruc/702825078836.pdf

INEGI, 2016, Resultados del procesamiento de información de la Encuesta Intercensal 2015. Grupo de trabajo técnico de Coordinación Interinstitucional Especializada del Gobierno de México. Disponible en https://docplayer.es/53640609-Coordinacion-interinstitucional-especializada-cie.html

Jiménez, L F., 2018, La inmigración laboral latinoamericana a las ciudades de México, Guadalajara y Monterrey, 1990-2015. Tesis Flacso, Ciudad de México.

Lesser, G. y Batalova, J., 2017, Inmigrantes centroamericanos en los Estados Unidos, Migration Policy Institute. Consultado el 5/06/2017. Disponible http://www. migrationpolicy.org/article/inmigrantes-centroamericanos-en-los-estados-unidos

Martínez Pérez, L. y Aznar Molina, Y., 2017, “Perfil sociodemográfico e inserción laboral y familiar de los cubanos y colombianos residentes en México de 1990 a 2004", en Migrantes latinoamericanos: el estado de las investigaciones en la región, red movilidad internacional de la población, Ed. Universidad de Córdoba, Córdoba, Argentina, pp. 235-25. Consultado el 5/06/2019. Disponible en http:// www.alapop.org/alap/SerieInvestigaciones/InvestigacionesSI1aSi9/MigrantesALYC-11.pdf

Martínez, O. y Martínez, J., 2018, El niño de Hollywood. Cómo Estados Unidos y El Salvador moldearon a un sicario de la mara salvatrucha, México, Debate.

Martínez, O., 2010, Los migrantes que no importan. Elfaro sur+. México.

Martínez, O., 2016. Una historia de violencia. Vida y muerte en América Central. México. Penguin Random House, Debate

Masferrer, C. y Pederzini, C., 2017, "Más allá de transito: perfiles diversos de la población del triángulo norte de Centroamérica residente en México", en Coyuntura demográfica, núm. 2, pp. 41-51, Disponible en http://www.somede.org/ coyuntura-demografica/pdf/numero12/masferrer-pederzini.pdf

Mosquera, Antonio, 1990, Los trabajadores guatemaltecos en México. Guatemala: Ed. Tiempos Modernos.

Naciones Unidas, 2016, Los desplazamientos del triángulo norte de Centroamérica constituyen una crisis humanitaria, Centro de Noticias ONU. Consultado 
el 31/05/2017. Disponible en http://www.un.org/spanish/News/story.asp?New$\mathrm{sID}=35200 \#$.WS8Sqes1_IU

Nájar, A., 2013, La migración que puede ser una pesadilla para México, BBC Mundo. Consultado el 16/07/2013. Disponible en https://www.animalpolitico. com/2013/07/la-migracion-que-puede-ser-una-pesadilla-para-mexico/

Nájera Aguirre, Jéssica Natalia, 2016, “El complejo estudio de la actual migración en tránsito por México: Actores, temáticas y circunstancias”, en Migraciones Internacionales, vol. 8, núm. 3: 255-266.

OIM, 2015, Hunger Without Borders, 2015. International Organization for Migration.

Ordóñez, César, 1989, Un análisis sobre aspectos del desarrollo agrícola y migración de fuerza de trabajo en regiones fronterizas de Chiapas y Guatemala. Informe final de investigación. San Cristóbal de las Casas: Centro de Investigaciones Ecológicas del Sureste y Asociación Mexicana de Estudios de Población.

Palma, M., 2006, De tierras extrañas-Un estudio sobre la inmigración en México, 1950-1990, Secretaría de Gobernación, Instituto Nacional de Migración, Centro de Estudios Migratorios e Instituto Nacional de Antropología e Historia, Ciudad de México.

Pardo y Dávila, 2017, "Población Extranjera residente en México. Caracterización demográfica y laboral 1990-2010", en Revista Entorno Geográfico, núm. 14, pp. 8-32. Consultado el 10/07/2018. Disponible en file://C:/Users/Felipe\%20Jch/ Desktop/7056-Texto\%20del\%20art\%C3\%ADculo-22662-1-10-20170921.pdf

Peña de la, A., 2015, El proceso de incorporación de los inmigrantes salvadoreños a la Ciudad de México. UNAM, Facultad de Ciencias Políticas y Sociales. Tesis UNAM, Ciudad de México.

Programa Mundial de Alimentos, 2017, “Seguridad Alimentaria y Emigración. Por qué la gente huye y el impacto que esto tiene en las familias que permanecen en El Salvador, Guatemala y Honduras". Programa Mundial de Alimentos. Consultado el 1/06/2017. Disponible en https://docs.wfp.org/api/documents/ WFP $-0000019633 /$ download/

Rodríguez, E., 2010, Extranjeros en México. Continuidades y nuevas aproximaciones, Instituto Nacional de Migración, Ciudad de México.

Rodríguez, E., 2016, Migración centroamericana en tránsito irregular por México. Nuevas cifras y tendencias. Centro América-Norte América Diálogos de migración. Series Población México. Consultado el 20/06/2019. Disponible en http://www.canamid.org/publication?id=PB014

Yankelevich, P., 2011, ¿Deseables o inconvenientes? Las fronteras de la extranjería en el México posrevolucionario, Ed. Bonilla Artigas, Ciudad de México 
Poblaciones guatemaltecas, hondureñas y salvadoreñas en México: perfiles propios y comparados ... / L.F. JIMÉNEZ y R. CASILLAS

Zazueta, Carlos y Pablos, Luis, 1982, Migrantes centroamericanos en México: primer informe preliminar de trabajadores centroamericanos a la república mexicana. México: CENIET.

\section{RESUMEN CURRICULAR DE LOS AUTORES}

\section{Luis Felipe Jiménez Chaves}

Egresado de la Maestría en Población y Desarrollo de la Facultad Latinoamericana de Ciencias Sociales, Sede México. Especialista en Estadística Aplicada de la Universidad del Valle y Economista de la Universidad del Cauca en Colombia. Ha impartido cursos universitarios de análisis de datos, econometría y macroeconomía. Sus principales áreas de interés se centran en la inmigración laboral, estructura y dinámica de los mercados de trabajo.

Dirección electrónica: luis.jimenez@estudiante-flacso.mx

Registro ORCID: http://orcid.org/0000-0001-6197-9070

\section{Rodolfo Casillas Ramírez}

Profesor investigador de la Facultad Latinoamericana de Ciencias Sociales, Sede México. Miembro del Consejo Consultivo del Instituto Nacional de Migración (2007-2012) y Miembro, para efectos consultivos, de la Comisión Intersecretarial sobre Trata de Personas del gobierno de México (2009-2012 y 2016-2017). Miembro del Comité editorial de la Revista Trace, publicación especializada en ciencias sociales del Centro de Estudios Mexicanos y Centroamericanos (CEMCA) (2014- 2017). Sus principales investigaciones comprenden en el plano conceptual y teórico: La construcción de identidades y espacios sociales de los grupos subalternos fuera del ámbito institucional. En el plano de la investigación empírica: Trata de personas en México; Migraciones internacionales de centroamericanos y mexicanos a Estados Unidos y procesos sociorreligiosos en México, con particular atención a las minorías religiosas.

Dirección electrónica: rodolfo.casillas@flacso.edu.mx

Registro ORCID: http://orcid.org/0000-0003-0862-7708 